\title{
The scavenging processes controlling the seasonal cycle in Arctic sulphate and black carbon aerosol
}

\author{
J. Browse ${ }^{1}$, K. S. Carslaw ${ }^{1}$, S. R. Arnold ${ }^{1}$, K. Pringle ${ }^{1}$, and O. Boucher ${ }^{2, *}$ \\ ${ }^{1}$ Institute for Climate and Atmospheric Science (ICAS), University of Leeds, Leeds, UK \\ ${ }^{2}$ Met Office, Exeter, UK \\ * now at: the Météorologie Dynamique, IPSL/CNRS, Univ. P. et M. Curie, 4 place Jussieu, 75252 Paris Cedex 05, France
}

Correspondence to: J. Browse (eejb@leeds.ac.uk)

Received: 6 January 2012 - Published in Atmos. Chem. Phys. Discuss.: 31 January 2012

Revised: 26 June 2012 - Accepted: 19 July 2012 - Published: 1 August 2012

\begin{abstract}
The seasonal cycle in Arctic aerosol is typified by high concentrations of large aged anthropogenic particles transported from lower latitudes in the late Arctic winter and early spring followed by a sharp transition to low concentrations of locally sourced smaller particles in the summer. However, multi-model assessments show that many models fail to simulate a realistic cycle. Here, we use a global aerosol microphysics model (GLOMAP) and surface-level aerosol observations to understand how wet scavenging processes control the seasonal variation in Arctic black carbon (BC) and sulphate aerosol. We show that the transition from high wintertime concentrations to low concentrations in the summer is controlled by the transition from ice-phase cloud scavenging to the much more efficient warm cloud scavenging in the late spring troposphere. This seasonal cycle is amplified further by the appearance of warm drizzling cloud in the late spring and summer boundary layer. Implementing these processes in GLOMAP greatly improves the agreement between the model and observations at the three Arctic groundstations Alert, Barrow and Zeppelin Mountain on Svalbard. The $\mathrm{SO}_{4}$ model-observation correlation coefficient $(R)$ increases from: -0.33 to 0.71 at Alert $\left(82.5^{\circ} \mathrm{N}\right)$, from -0.16 to 0.70 at Point Barrow $\left(71.0^{\circ} \mathrm{N}\right)$ and from -0.42 to 0.40 at Zeppelin Mountain $\left(78^{\circ} \mathrm{N}\right)$. The $\mathrm{BC}$ model-observation correlation coefficient increases from -0.68 to 0.72 at Alert and from -0.42 to 0.44 at Barrow. Observations at three marginal Arctic sites (Janiskoski, Oulanka and Karasjok) indicate a far weaker aerosol seasonal cycle, which we show is consistent with the much smaller seasonal change in the frequency of ice clouds compared to higher latitude sites. Our results suggest that the seasonal cycle in Arctic aerosol is driven
\end{abstract}

by temperature-dependent scavenging processes that may be susceptible to modification in a future climate.

\section{Introduction}

The effects of climate change are amplified in the Arctic, with projected temperature increases of $5^{\circ} \mathrm{C}$ predicted before the year 2100 (IPCC, 2007). This amplified warming is manifested in the rapid decline in sea ice extent over the past few decades (Comiso, 2002). The retreat of Arctic sea ice could shift patterns of atmospheric circulation, increase coastal erosion and disrupt the ocean thermohaline cycle as well as devastate the fragile Arctic ecosystem (Serreze et al., 2007). Furthermore, the decrease in planetary albedo may lead to an acceleration of global and regional warming through the albedo feedback described in Curry et al. (1995).

The increase in Arctic surface temperatures since the mid1970s is estimated to be between 1.2 and $1.8^{\circ} \mathrm{C}$ (Shindell and Faluvegi, 2009). The modelling study of Shindell and Faluvegi (2009) suggests that less than one-third of this warming can be explained by changes in either greenhouse gas concentrations or the Arctic ozone budget. Changes in anthropogenic aerosol, particularly the decrease in global sulphate emissions since the late 1980 s, may account for up to $1^{\circ} \mathrm{C}$ of the observed warming trend between 1976 and 2008.

Anthropogenic aerosols, both in the atmosphere or deposited on ice and snow, have been observed in the Arctic since the 1880s (Garrett and Verzella, 2008). The high concentrations of aerosol observed in the Arctic spring, now referred to as Arctic haze, were first identified in the 1950s by 
Mitchell (1956). Analysis of the haze constituents by Rahn et al. (1977) and Shaw (1982) found a signature of Asian sources, and from the 1980s onwards numerous studies have confirmed the anthropogenic origin of Arctic haze events in the early spring (Gong and Barrie, 2005; Fisher et al., 2010; Hirdman et al., 2010; Sharma et al., 2006; Reddy and Boucher, 2007).

A strong seasonal cycle in Arctic sulphate and BC aerosol mass concentrations is evident in long term observations at Point Barrow in Alaska (Sharma et al., 2006; Quinn et al., 2009, 2002), Zeppelin Mountain on Svalbard (Eleftheriadis et al., 2009; Ström et al., 2003) and Alert in Canada (Gong et al., 2010).The Arctic haze forms due to the strong temperature inversion over the Arctic, which facilitates the ascent of transported pollutant plumes from lower latitudes over the pole. The cold dry conditions of the Arctic winter, which suppress removal via wet deposition, and the suppression of vertical mixing by the polar inversion are thought to provide suitable conditions for transported pollutants to accumulate over the winter and early spring (Shaw, 1995). This situation persists until the beginning of summer when changes to transport pathways (Stohl, 2006), the onset of vertical mixing due to solar heating (Kahl et al., 1996), and increases in wet scavenging remove existing aerosol and hinder further aerosol transport from low latitudes.

An analysis of observations at Barrow (Garrett et al., 2010, 2011) found that the onset of local wet scavenging may be the dominant process controlling low summertime aerosol, rather than changes in the efficiency of aerosol transport to Barrow. The inefficient long-range transport in the summer means that summertime aerosol is sourced from the marginal Arctic (sea-ice boundary and boreal forest regions) and probably consists of episodic soot from forest fires (Warneke et al., 2010), sulphate from dimethyl sulphide (DMS) emitted from the ocean surface (Ferek et al., 1995; Lunden et al., 2010), and sea-spray (Yang et al., 2008). Here, we suggest that the low aerosol concentrations observed in the Arctic boundary layer north of $70^{\circ} \mathrm{N}$ are the result of the cumulative effect of drizzling low clouds at high latitudes on these sources (see Sect. 7.2).

Analysis of decadal trends indicates that while summertime ground-station concentrations (with the exception of Barrow) have changed little since the 1970s, in winter and spring sulphate and equivalent black carbon (EBC, see Sect. 2) concentrations have declined over the last $20 \mathrm{yr}$ (Quinn et al., 2007; Hirdman et al., 2010). This decline in both $\mathrm{BC}$ and $\mathrm{SO}_{4}$ is also evident in central Greenland ice-cores (McConnell et al., 2007). The global decrease in aerosol concentrations resulting from stricter air quality controls in Europe and North America (IPCC, 2007) is a possible cause of this decline. However, the North Atlantic Oscillation (NAO) also strongly influences pollution transport to high latitudes with positive phases of the NAO shown to enhance winter surface pollutants by up to $70 \%$ (Eckhardt et al., 2003). Between 1970 and 2000 the NAO index for December to February was on average strongly positive $(\sim 2)$ compared to the average low negative index between 2000 and 2010 (seasonal NAO indices obtained from Hurrell, 2011). The recent decline in Arctic aerosol concentrations between winter and early spring is therefore most likely the result of a reduction in source emissions combined with a weakening of transport pathways post-2000.

Alternatively, it has also been shown (Vinogradova and Ponomareva, 2000) that scavenging efficiency, to which Arctic aerosol concentrations are particularly sensitive (Shindell et al., 2008), in liquid-phase clouds is far greater then that in ice-phase (see Sect. 5.1). Therefore it may be that the increase in global temperatures since the 1970s (IPCC, 2007) has increased the ratio of liquid to ice-phase cloud scavenging and so decreased the efficiency of long range-transport into the Arctic. Currently, little evidence exists to support or refute this hypothesis. Here, we suggest that wintertime Arctic scavenging rates are relatively insensitive to temperature increases of less than $5^{\circ} \mathrm{C}$ (see Sect. 7.3.2).

At Barrow, in addition to the winter decline in aerosol concentrations, a summertime increase in non-sea-salt (nss) $\mathrm{SO}_{4}$ of 8 to $12 \%$ per year has been observed from 1976 to 2008 . This increase in nss- $\mathrm{SO}_{4}$ mass coincides with an equivalent increase in methane sulphonic acid (MSA) concentration, a by-product of DMS oxidation to $\mathrm{SO}_{2}$. Increases in MSA concentration suggest that climatic changes (i.e. increasing sea surface temperature) in the Arctic may be altering atmospheric DMS concentrations (Quinn et al., 2009), although this hypothesis is not explored here. In addition to increasing DMS concentrations it is likely that a decline in Arctic sea-ice extent (coupled with increases in wind speed) will increase sea-salt aerosol concentrations in the Arctic boundary layer (Jones et al., 2007; Struthers et al., 2011). However, to the knowledge of the authors no observational evidence exists to support this hypothesis.

In a multi-model assessment, Shindell et al. (2008) compared 13 models against measured EBC and sulphate mass concentrations at Alert, Barrow and Svalbard. They found that the majority of models significantly underestimated both $\mathrm{BC}$ and $\mathrm{SO}_{4}$ concentrations through January to May while overestimating summertime $\mathrm{SO}_{4}$. In almost half of the models the seasonal cycle in sulphate mass concentration was approximately 6 months out of phase with observations. Korhonen et al. (2008b) compared simulated aerosol size distributions in a particle size-resolving aerosol microphysics model (Spracklen et al., 2005) with observations at Zeppelin mountain on Svalbard (Ström et al., 2003) and again found them to be seasonally out of phase, with larger particles dominating the summertime size distribution. Both studies looked in detail at the sensitivity of the seasonal cycle to different deposition processes and found aerosol concentrations to be extremely sensitive to changes to modelled wet deposition rates.

Here, two new deposition parametrisations, ice-cloud and low-cloud scavenging, have been added to the global aersol 
model GLOMAP-mode (Mann et al., 2010) to understand how changes to the local and global scavenging distribution affect the Arctic $\mathrm{SO}_{4}$ and $\mathrm{BC}$ aerosol seasonal cycle. Through analysis of observed and modelled sulphate and $\mathrm{BC}$ aerosol surface concentrations it was demonstrated that the rapid shift in aerosol characteristics observed in the late springtime Arctic boundary layer is strongly controlled by the local onset of warm (liquid) cloud nucleation scavenging in the low Arctic troposphere.

\section{Observations}

Simulated surface $\mathrm{SO}_{4}$ mass concentrations are evaluated using measured concentrations at three high latitude Arctic ground-stations: Zeppelin mountain on Svalbard $\left(78.9^{\circ} \mathrm{N}\right.$, $11.9^{\circ} \mathrm{E}, 474 \mathrm{~m}$ a.s.l.), Alert station in the Canadian Arctic $\left(82.5^{\circ} \mathrm{N}, 62.5^{\circ} \mathrm{W}, 210 \mathrm{~m}\right.$ a.s.l.), and Point Barrow in northern Alaska $\left(71^{\circ} \mathrm{N}, 156.6^{\circ} \mathrm{W}, 11 \mathrm{~m}\right.$ a.s.l.). Below $70^{\circ} \mathrm{N}, \mathrm{SO}_{4}$ measurements were also available from three ground stations in the EMEP network (http://www.emep.int/): Karasjok in Norway $\left(69^{\circ} \mathrm{N}, 24^{\circ} \mathrm{E}\right)$, Janiskoski in Russia $\left(68.5^{\circ} \mathrm{N}\right.$, $\left.28.5^{\circ} \mathrm{E}\right)$, and Oulanka in Finland $\left(66^{\circ} \mathrm{N}, 29^{\circ} \mathrm{E}\right)$. The locations of all six sites are shown in Fig. 1. Observations from field campaigns at higher latitudes (above $85^{\circ} \mathrm{N}$ ) were not used in this evaluation since they cover only short periods and the focus of this study is on the annual cycle.

Mass concentrations of non-sea-salt (nss) $\mathrm{SO}_{4}$ at Zeppelin were sourced from the Norwegian institute for air research (NILU) database (www.nilu.no/projects/ccc/create/database. $\mathrm{htm}$ ) as daily concentrations which were then converted to monthly means after the removal of statistical outliers (here assuming a normal distribution defined as data points greater then 1.5 standard deviations from the monthly mean). The particle size measured at Zeppelin was limited to below $10 \mu \mathrm{m}$. However, at this latitude this size limit is unlikely to have a significant impact on measured mass concentrations.

At Barrow weekly sampled nss- $\mathrm{SO}_{4}$ mass concentrations for both submicron (diameter $\leq 0.1 \mu \mathrm{m}$ ) and supermicron $(0.1 \mu \mathrm{m} \leq$ diameter $\leq 10 \mu \mathrm{m})$ particulates were sourced from the NOAA archive (ftp://ftp.cmdl.noaa.gov/aerosol/ brw/chem/). $\mathrm{SO}_{4}$ mass concentrations at Barrow were sampled over different time periods (ranging from 1-5 days) depending on the season and the size range. The two datasets were averaged over each month with statistical outliers removed within each. Both the submicron and supermicron monthly averaged $\mathrm{SO}_{4}$ mass concentrations were then added to give the total monthly mean sulphate mass concentration for particulates below $10 \mu \mathrm{m}$ in diameter.

Weekly sampled sulphate mass concentrations at Alert are available from the Canadian National Chemistry (NatChem) database (http://www.msc.ec.gc.ca/natchem/particles/index e.html) and were converted to monthly mean concentrations. At the EMEP sites $\mathrm{SO}_{4}$ observations were taken directly from the EMEP database already converted to monthly mean
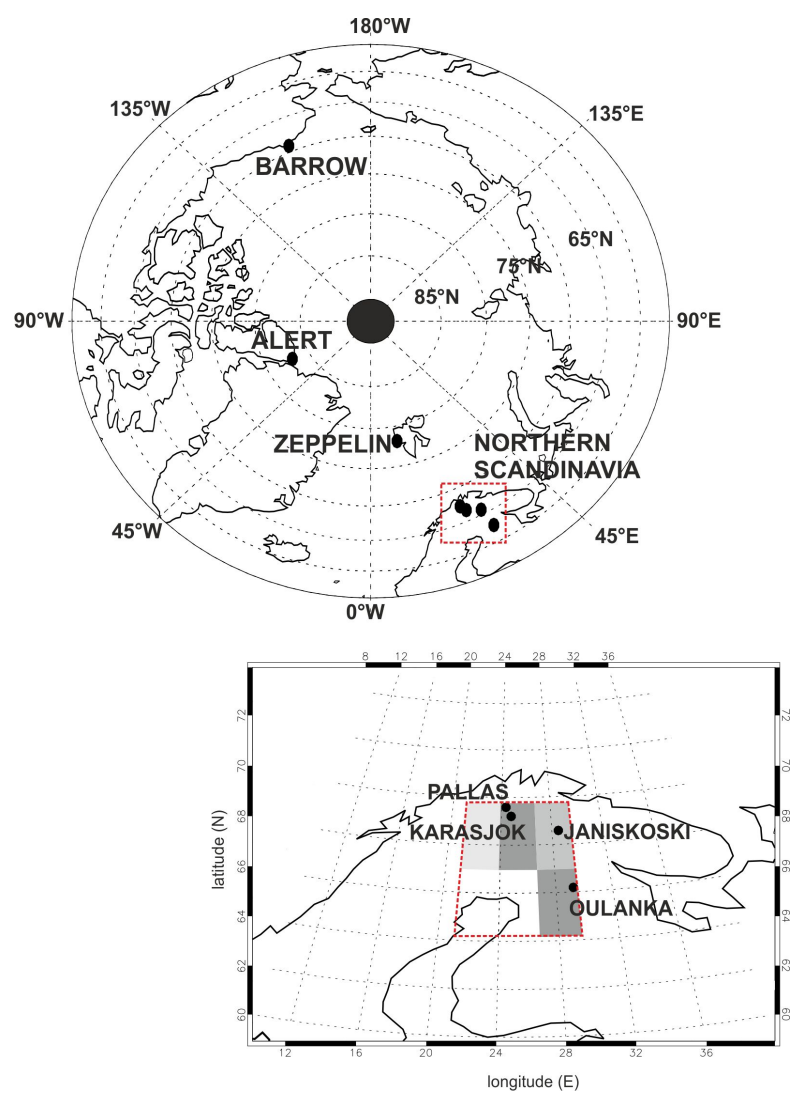

Fig. 1. Model projection of the Arctic. The Arctic ground-stations: Alert $\left(62.5^{\circ} \mathrm{W}, 82.4^{\circ} \mathrm{N}\right)$, Barrow $\left(156.6^{\circ} \mathrm{W}, 71.3^{\circ} \mathrm{N}\right)$ and Zeppelin mountain $\left(11.9^{\circ} \mathrm{E}, 78.9^{\circ} \mathrm{N}\right)$ are labelled and the Northern Scandinavian sites: Oulanka $\left(29.2^{\circ} \mathrm{E}, 66.2^{\circ} \mathrm{N}\right)$, Janiskoski $\left(28.5^{\circ} \mathrm{E}\right.$, $\left.68.6^{\circ} \mathrm{N}\right)$ and Karasjok $\left(25.1^{\circ} \mathrm{E}, 69.3^{\circ} \mathrm{N}\right)$ are shown (red box). The bottom projection shows both the position of the latter three stations which are in close proximity to each other and the three model grid-boxes which represent this region (grey shading). The region outlined in red represents the model region used to calculate the Northern Scandinavian average used in Fig. 7d.

mass concentrations. Given the close proximity of the EMEP stations (in the context of the model resolution - see Fig. 1) and the consistency of observations in this region $(\sigma=0.08)$, observations from all three stations were averaged to produce a single mass concentration.

Long-term BC mass concentration datasets were available only at Alert and Barrow, which limits model evaluation of $\mathrm{BC}$ concentrations to the Canadian and Alaskan Arctic. The majority of long-term $\mathrm{BC}$ measurements are derived from measurements of light absorption and so are termed equivalent black carbon (EBC). EBC is calculated using the total light absorption coefficient of an air sample so EBC concentrations are likely to overestimate BC mass due to the presence of other light absorbing aerosol species. This overestimation can be compensated for by the choice of a mass absorption efficiency (MAE) calibrated from 
alternative (usually thermal) BC measurements (Sharma, 2002; Sharma et al., 2004). At Barrow hourly measured light absorption coefficients were available from the World Data Centre for Aerosols archive (http://wdca.jrc.ec.europa. $\mathrm{eu} / \mathrm{sites} / \mathrm{brw} / \mathrm{brw}$ _labs.html) and converted to mass concentration using an MAE of $10 \mathrm{~m}^{2} \mathrm{~g}^{-1}$ as recommended by the principal investigators and discussed in Sharma (2002).

Hourly EBC mass concentrations at Alert were obtained from the World Data Centre for Aerosols (WDCA - http:// wdca.jrc.ec.europa.eu/sites/alt/alt_ebc.html). Unlike Barrow, EBC measurements at Alert have been compared with alternative measurements from thermal filter sample analysis (Sharma et al., 2004). EBC measurements at Alert derived using a MAE of $19 \mathrm{~m}^{2} \mathrm{~g}^{-1}$ and thermally derived BC measurements were found to compare well with a $R^{2}$ correlation of 0.82 and a slope and intercept of 0.85 and $0.09 \mu \mathrm{g} \mathrm{m}^{-3}$, respectively when fitted with a linear regression. In light of this comparison EBC measurements at Alert were derived from a seasonally varying specific absorption coefficient of $19.8 \mathrm{~m}^{2} \mathrm{~g}^{-1}$ from November to April and $28.8 \mathrm{~m}^{2} \mathrm{~g}^{-1}$ from May to October as described in Sharma et al. (2004). At both ground-stations EBC was converted from hourly measurements to monthly mean concentrations after the elimination of statistical outliers (as discussed above).

At the Alert and Barrow sites different instruments are used to measure equivalent black carbon concentrations so the two datasets are not directly comparable. The major uncertainty in these measurements is the presence of secondary absorbing species in the particles, which results in an overestimate of refractory black carbon mass. Due to the seasonality of aerosol mass concentration at Arctic sites the use of uniform MAE (such as at Barrow) is likely to overestimate summer BC mass while underestimating winter BC mass. The inter-annual variability of Arctic aerosol is also high so it is likely that from year to year the agreement of EBC mass with actual $\mathrm{BC}$ varies considerably. In this study we focus on reproducing the seasonal cycle (and in particular the late-spring transition) of $\mathrm{BC}$ and for this purpose these observations are applicable. However, quantitative comparison of these observations with the model (below) will be affected by this uncertainty.

\section{Model description}

GLOMAP-mode is a global microphysical aerosol model (Mann et al., 2010) developed as an extension of the offline TOMCAT chemical transport model described in Stockwell and Chipperfield (1999). The model treats the aerosol size distribution using a two-moment modal scheme with 7 lognormal modes (4 soluble and 3 insoluble) and the 5 aerosol species dust, sea salt, $\mathrm{BC}$, organic carbon (OC) and $\mathrm{SO}_{4}$. The 7 modes fall into four variable-size size categories: nucleation $(\sim 3-15 \mathrm{~nm})$, Aitken $(\sim 10-50 \mathrm{~nm})$, accumulation $(\sim 50-200 \mathrm{~nm})$ and coarse $(\sim 1000 \mathrm{~nm})$. Concen- trations of oxidants are specified offline every $6 \mathrm{~h}$ from a previous TOMCAT simulation (Arnold et al., 2005). Evaluation of GLOMAP-mode in the mid-latitudes and tropics suggest that the model performs well against observational datasets although black and organic carbon surface mass concentrations are underestimated in some regions (Mann et al., 2010).

The model was run at a horizontal resolution of $2.8^{\circ} \times 2.8^{\circ}$ (latitude $\times$ longitude) with 31 pressure levels extending from the surface to $10 \mathrm{hPa}$ (approximately $40 \mathrm{~km}$ ) in the vertical. Meteorological fields of horizontal wind speed, temperature and humidity were taken from analyses of the European Centre for Medium-Range Weather Forecasts (ECMWF). The ECMWF analyses compare well with other analyses and describe the meteorology of the Arctic region reasonably well (Bromwich et al., 2007).

The model was run from January 2000 to December 2002 using annually-varying anthropogenic $\mathrm{BC}$, organic carbon (OC) and $\mathrm{SO}_{2}$ emission inventories from the AEROCOM hindcast database (http://dataipsl.ipsl.jussieu.fr/AEROCOM/ emissions.html). AEROCOM inventories were also used for volcanic $\mathrm{SO}_{2}$ while wildfire emissions were updated each month from the global fire emissions database version 2 (GFED) (Randerson et al., 2007). We assume that $2.5 \%$ of the $\mathrm{SO}_{2}$ from anthropogenic, volcanic and wildfire sources is emitted as $\mathrm{SO}_{4}$ as recommended by Stier et al. (2005) to represent sub-grid nucleation and growth of new particles. The sub-grid nucleated $\mathrm{SO}_{4}$ particles are partitioned equally between two lognormal size modes of geometric mean diameter 60 and $150 \mathrm{~nm}$, respectively with a geometric standard deviation of 0.59 (Stier et al., 2005).

The microphysical processes in GLOMAP-mode include coagulation between and within modes, wet and dry deposition, ageing of $\mathrm{BC} / \mathrm{OC}$ mixed particles from an initial insoluble state to water soluble, oxidation of $\mathrm{SO}_{2}$ into $\mathrm{SO}_{4}$ in cloud drops, condensation growth between modes (due to uptake of sulphuric acid and secondary organic vapours), and nucleation of $\mathrm{SO}_{4}$ aerosol (Mann et al., 2010).

Wet deposition occurs in frontal and convective precipitating clouds by nucleation scavenging (due to activation of CCN into cloud drops and subsequent precipitation) and impaction scavenging of aerosol particles by falling raindrops. All water-soluble particles larger than $103 \mathrm{~nm}$ wet diameter are assumed to act as activated $\mathrm{CCN}$ in grid-boxes where precipitation has been diagnosed. The reason for using a diameter threshold to determine CCN populations is historic stemming from the use of a sectional size-resolving bin scheme in previous model versions. The aerosol wet diameter in GLOMAP is calculated from the dry diameter using the relative humidity diagnosed from the ECMWF temperature, pressure and specific humidity meteorological fields. Thus, at relative humidity between 70 and $80 \%$ this process activates all aerosol with dry diameter greater than $\sim 60 \mathrm{~nm}$ and at relative humidities greater than $80 \%$ aerosol with diameter greater than $\sim 50 \mathrm{~nm}$ are activated. The fraction of activated 
aerosol removed in a time-step is assumed to be equal to the fraction of condensate precipitated.

Occurrences of precipitating clouds are calculated from the ECMWF analyses used to drive the model (Pringle, 2006). In convective clouds the fraction of condensate is calculated from the precipitating water downward mass flux parameterised in the model via the methodology of Tiedtke (1989). Convective rain is assumed to be a sub-grid process that occurs in only $30 \%$ of a grid-box (Giannakopoulos et al., 1999). In contrast, frontal rain scavenging is assumed to occur over an entire grid-box. Frontal rain is diagnosed from the ECMWF humidity profile (Mahowald et al., 1997; Giannakopoulos et al., 1999) and is assumed to remove $100 \%$ of CCN during one model time step (Giannakopoulos et al., 1999).

In the baseline model, monthly resolved low cloud climatologies are taken from the International Satellite Cloud Climatology Project (ISCCP) database (Rossow and Duenas, 2004) which provides low-cloud fraction and cloud top pressure (converted in GLOMAP to vertical cloud fraction). Low (boundary layer) clouds are assumed not to precipitate, but only affect aerosol through aqueous phase oxidation of $\mathrm{SO}_{2}$ to $\mathrm{SO}_{4}$ by ozone and hydrogen peroxide (Mann et al., 2010). In several of the perturbed runs used in this study the IS$\mathrm{CCP}$ fields are merged at $60^{\circ} \mathrm{N}$ with data from the MODerate resolution Imaging Spectrometer (MODIS) satellite (see Sect. 4). MODIS has been shown to measure Arctic cloud fraction with greater accuracy (compared to surface climatologies) than other instruments (Liu et al., 2004). This substitution is discussed further in Sect. 4.

\section{Low-level cloud}

At high latitudes in the summer, the relatively high humidity allows the formation of low-level stratocumulus cloud decks in the boundary layer and lower troposphere. These low-level clouds and fogs produce frequent drizzle and can be present for as much as $90 \%$ of the time (Curry et al., 1996; Lawson et al., 2001). It has been suggested that the low summertime aerosol concentrations can be explained by this increase in scavenging combined with a decrease in transport from outside the Arctic (Stohl, 2006).

In previous model versions monthly resolved low cloud fraction and cloud top pressure climatologies were sourced from ISCCP (Rossow and Schiffer, 1999). ISCCP cloud fractions north of $60^{\circ} \mathrm{N}$ have a median cloud fraction from 0 to 0.1 with generally higher fractions in summer and a maximum 95th percentile in April of 0.25 (Fig. 2). Although the temporal pattern in ISCCP cloud fraction is consistent with observations, the magnitude of cloud cover is significantly underestimated compared to observations from the Arctic surface, which rarely fall below 0.50 and can be as high as 0.90 (Curtis et al., 1998; Hahn et al., 1995). The satellite detection of polar clouds is complicated by the thermal and vis-

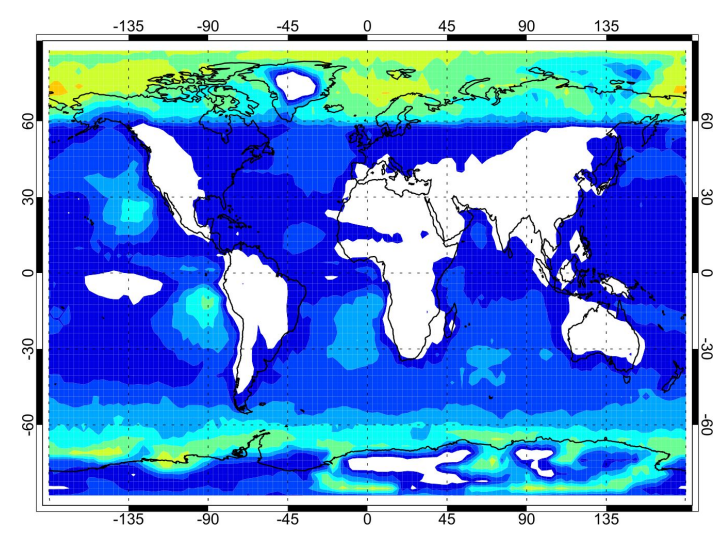

(a) JJA mean low-cloud fraction (MODIS/ISCCP merged climatologies)

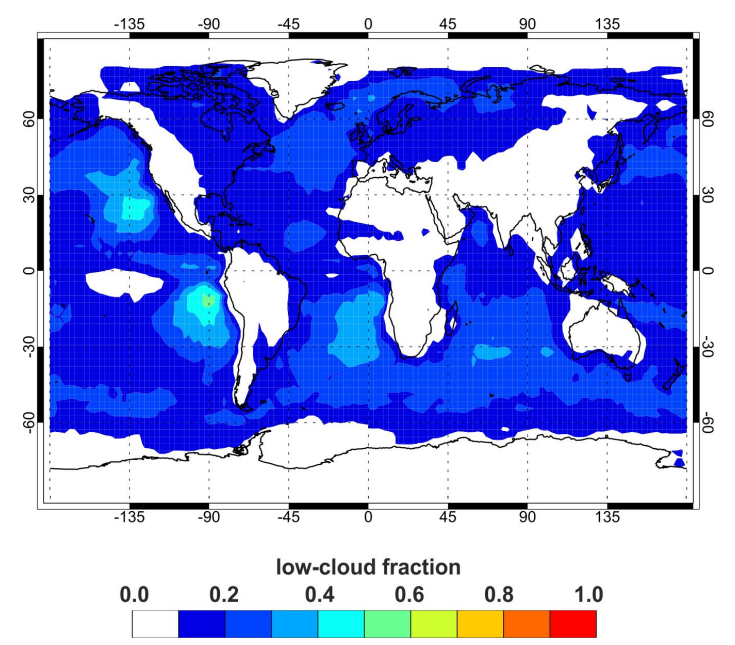

(b) JJA mean low-cloud cover (ISCCP climatologies)

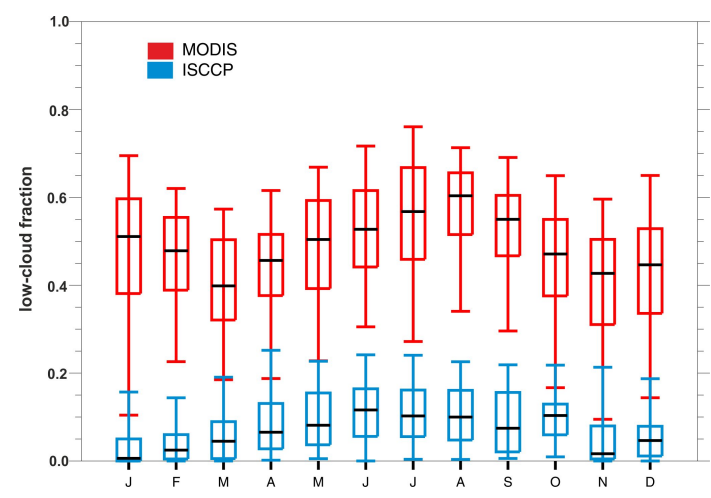

(c) low cloud fraction between $60-90^{\circ} \mathrm{N}$

Fig. 2. Comparison of the merged MODIS/ISCCP (see section 4) and ISCCP low-cloud climatologies. (a-b) show the JJA average column maximum low cloud fraction in the MODIS/ISCCP (a) and ISCCP (b) climatologies. Note: white here indicates maximum cloud fraction below $10 \%$. (c) compares the MODIS (red) and ISCCP (blue) median low cloud fraction between 60 and $90^{\circ} \mathrm{N}$. Errors bar denote the 5th and 95th percentiles for each month, while the box plots show the interquartile range of the median. 
ible similarity between clouds and ice-snow surfaces as well as the pervasive temperature and humidity inversions in the Arctic boundary layer (Liu et al., 2004). However, MODIS, which takes a greater frequency of high latitude observations, has been found to measure Arctic cloud fraction and cloud top pressure more accurately then other instruments (Liu et al., 2004).

In this study we merge cloud fractions from MODIS at high latitudes with ISCCP at low latitudes. Monthly resolved $1 \times 1^{\circ}$ cloud fraction and cloud top pressure data from the MODIS satellite (Hubanks et al., 2008) were interpolated to a $2.8^{\circ} \times 2.8^{\circ}$ resolution and merged with interpolated ISCCP climatologies using a exponential function to calculate a weighted mean cloud fraction such that in grid-box $\left(x_{\text {lon }}, y_{\text {lat }}\right)$ the low cloud fraction $\left(\mathrm{CF}_{x_{\text {lon }}, y_{\text {lat }}}\right)$ was calculated as:

$\mathrm{CF}_{x_{\text {lon }}, y_{\text {lat }}}=\frac{\mathrm{M}_{x_{\text {lon }}, y_{\text {lat }}} e^{-\lambda\left(y_{\text {lat }}-y_{60}\right)}+\mathrm{I}_{x_{\text {lon }}, y_{\text {lat }}} e^{-\lambda\left(y_{60}-y_{\text {lat }}\right)}}{e^{-\lambda\left(y_{\text {lat }}-y_{60}\right)}+e^{-\lambda\left(y_{60}-y_{\text {lat }}\right)}}$

where $\mathrm{M}$ and I are the MODIS and ISCCP cloud fractions, respectively and $\lambda$ is equal to 0.5 . Figure 2 shows the median low cloud fraction above $60^{\circ} \mathrm{N}$ for both the merged and ISCCP low cloud climatologies. In the merged climatologies cloud fraction has increased universally, with a 5th percentile greater than the ISCCP 95th percentile in the summer and greater than the upper quartile for the rest of the year. The use of $\lambda=0.5$ results in MODIS climatologies replacing ISCCP over only two latitude grid-boxes. However, with this method, median summertime cloud fraction north of $70^{\circ} \mathrm{N}$ increases to $50-60 \%$ equivalent to that observed (Curtis et al., 1998).

We chose to merge the datasets rather than using MODIS climatologies universally as global comparisons of the two datasets show that in the ISCCP climatology areas of higher cloud fraction coincide with the stratocumulus regions described in Leon et al. (2008), while in MODIS maximum cloud fractions occur over the equatorial region and the southern ocean. This disparity would suggest that, despite underestimating the magnitude of cloud fraction at high latitudes, ISCCP performs better than MODIS at lower latitudes. This conclusion is consistent with Leon et al. (2008) who found that ISCCP climatologies compared well with observations from the CloudSat instrument on the CALIPSO satellite.

\section{Model scavenging processes}

\subsection{Ice-cloud scavenging}

The in-cloud lifetime of activated $\mathrm{CCN}$ with respect to wet scavenging in liquid-phase clouds is of the order $1 \mathrm{~h}$ (Wood, 2006; Curry et al., 1996). In addition, in-cloud CCN lifetimes in liquid-phase clouds are generally independent of the cloud precipitation rate as liquid water path scales to the precipitation rate, leading to cancellation in Eq. (2) (see below, Wood,
2006). However, scavenging processes in ice-phase clouds are much less efficient and in-cloud CCN lifetime can extend to 1 month if ice-nucleation is the predominant scavenging process (Davidson et al., 1987; Vinogradova and Ponomareva, 2000). The principal reason for this difference is that precipitation-sized drops in liquid phase clouds grow primarily by collection, a process that collects both cloud droplets and aerosol. Conversely ice crystals tend to form via the nucleation of ice onto individual particles and grow by vapour deposition rather than collision and coalescence. Thus precipitation in liquid-phase clouds can scavenge aerosol particles much more efficiently (Vinogradova and Ponomareva, 2000).

In the standard version of GLOMAP-mode (our control simulations) scavenging rates of soluble aerosol are independent of temperature (see Fig. 3) with all cloud-phases assumed to scavenge equal numbers of soluble aerosol. This assumption is likely to overestimate global scavenging rates particularly in regions where inefficient ice cloud scavenging is prevalent. For insoluble aerosol, a cloud temperature threshold is used to determine scavenging rates. Above $-15^{\circ} \mathrm{C}$ insoluble $\mathrm{BC}$ aerosol is not scavenged and below $-15^{\circ} \mathrm{C}$ they act as IN and are scavenged at the rate of CCN of the same size (Fan, 2004) (Fig. 3). It is possible that this process overestimates the deposition of insoluble aerosol from ice nucleation. However, the majority of insoluble particles are small and exist in the Aitken mode (freshly emitted $\mathrm{BC}$ and $\mathrm{OC})$ and are therefore only weakly scavenged $(0.1 \%$ of the total global insoluble BC mass deposited) compared to impaction scavenging (22\%) and dry deposition (77.9\%). Thus, model assumptions about IN scavenging of insoluble $\mathrm{BC}$ particles have only a small effect on the model results.

To address the overestimation of soluble particle scavenging rates, we extended the cloud temperature threshold parameterisation also to soluble aerosol. In the absence of a well-defined temperature limit governing the onset of the ice-phase in clouds (Gayet et al., 2009b,a) the same limit of $-15^{\circ} \mathrm{C}$ was used to match the existing temperature threshold governing insoluble aerosol scavenging (Fan, 2004). Below this temperature, scavenging of soluble aerosol is prohibited, reflecting the absence of scavenging by coalescence and collision in ice-clouds, while insoluble particles continue (as in the standard model version) to act as ice nuclei (IN) (Baumgardner et al., 2008; Gorbunov et al., 2000).

This simple method of switching between efficient warmcloud scavenging and effectively non-scavenging ice clouds is expedient in a chemical transport model that does not include the cloud microphysical processes required to predict hydrometeor phase. It is also consistent with the analysis of Garrett et al. (2010), who identified a scavenging temperature switch in Arctic clouds, and the observations of Gayet et al. (2009a) and Curry et al. (1996) which show that Arctic clouds are in general dominated by either ice or liquid phase droplets. 


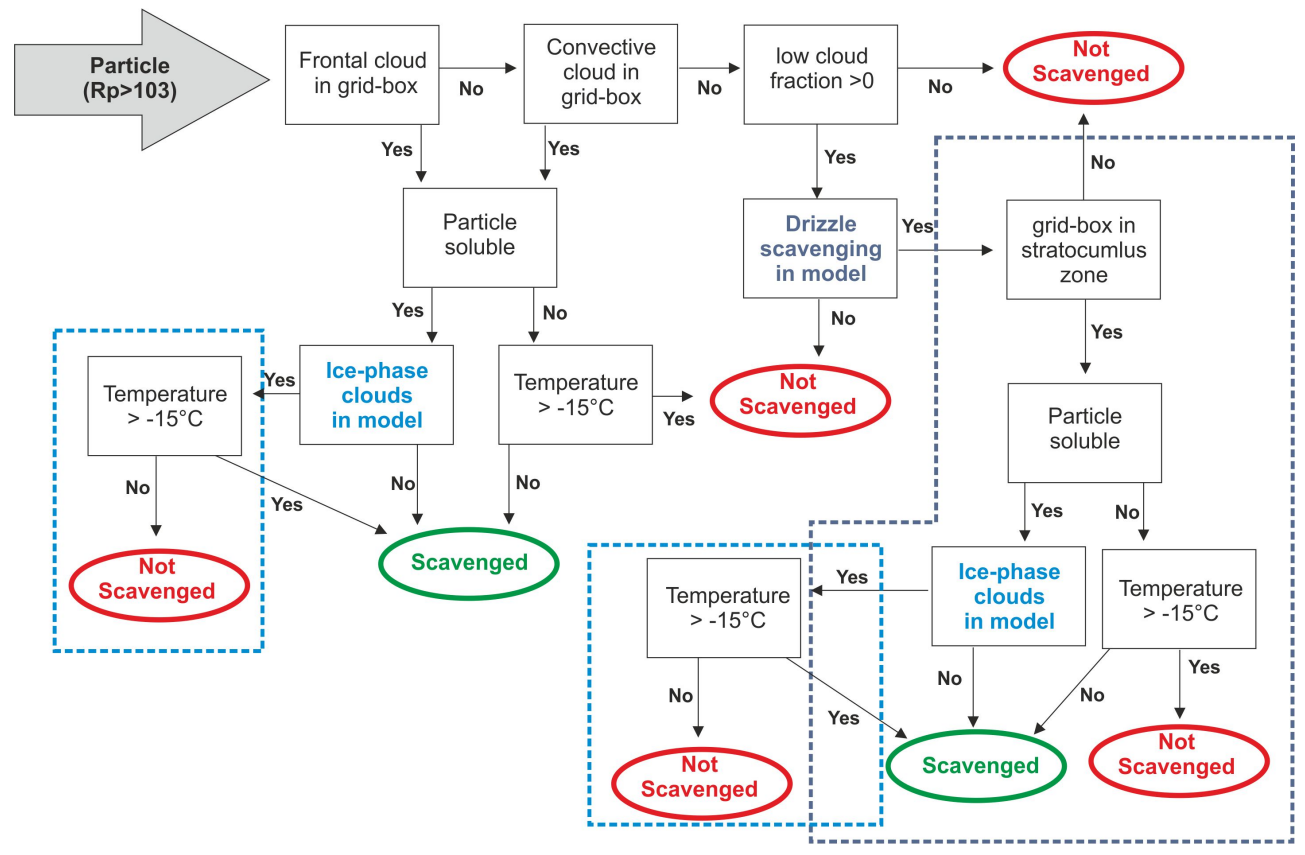

Fig. 3. Flowchart describing GLOMAP-mode nucleation scavenging scheme.

However, observations have shown that in spring mixedphase cloud is also present in the Arctic lower troposphere (Hobbs and Rangno, 1998). Mixed-phase cloud scavenging can occur via nucleation of ice on individual particles (as discussed above) and riming of ice particles with water droplets and is likely to have an efficiency between that of ice-nucleation scavenging and liquid-phase scavenging (Hegg et al., 2011) Therefore, our treatment of mixed-phase clouds as liquid-phase is likely to overestimate the scavenging rate in spring.

Mixed-phase cloud formation can occur over a wide temperature range. The scavenging efficiency of individual clouds is dependent on the ratio of liquid-to-total water, which is affected by physical processes such as the WegenerBergeron-Findeisen process and can be highly variable over limited temperature ranges (Smith et al., 2009). In models that include mixed-phase clouds (Bourgeois and Bey, 2011) assumptions still need to be made about scavenging rates that are not treated explicitly, and agreement with observations is not necessarily improved. Our switch from liquid to icephase at $-15^{\circ} \mathrm{C}$ is consistent with what is seen in observations (Garrett et al., 2010), and is a reasonable assumption until the physical processes are resolved better. The implications of the exclusion of mixed-phase scavenging are discussed below (Sect. 7.3.2).

Figure 4 shows the percentage of total precipitation falling to the surface as snow in GLOMAP-mode as defined by this ice-cloud temperature threshold. The ratio of modelled snow to rain is highest in the Arctic winter and early spring, where $90 \%$ of precipitation falls as snow above $60^{\circ} \mathrm{N}$ in Asia and above $70^{\circ} \mathrm{N}$ in Canada and Alaska. Comparison of the snow to rain ratio at different Arctic ground-stations indicates that, while in the winter Alert and Barrow are positioned in regions of negligible warm cloud scavenging, at Zeppelin, Oulanka, Karasjok and Janiskoski warm rain scavenging remains a significant removal mechanism throughout the winter and spring.

\subsection{Low-cloud scavenging by drizzle}

Local scavenging of aerosol in the Arctic can be caused by persistent light drizzle and sleet in the boundary layer as well as episodic dynamic rain fronts directed into the high latitudes by large scale meteorological systems. In GLOMAP, low-cloud precipitation is not treated in the standard model. Thus episodic large scale meteorological systems dominate scavenging north of $60^{\circ}$. More dynamic rain fronts reach the Arctic in winter than summer, although liquid precipitation (rain) is more likely in summer, with median values in summer of $\approx 1.5 \mathrm{~mm} \mathrm{~d}^{-1}$ compared to $0.5 \mathrm{~mm} \mathrm{~d}^{-1}$ in winter.

The reason for neglecting low cloud scavenging in GLOMAP-mode is historic: GLOMAP diagnoses precipitation in frontal clouds and convection (see Sect. 3), and wet deposition by these processes alone results in aerosol lifetimes of $\sim 1$ day that are well within the range of other models (Textor et al., 2006). In addition, given the uncertainties in marine aerosol and precursor emissions in regions where stratocumulus clouds are prevalent, it has not been possible to detect missing sinks when evaluating the model against observations (Spracklen et al., 2007; Korhonen et al., 2008a) (see also Sect. 7.5). Nevertheless, drizzle is a common occurrence in the summertime Arctic boundary 

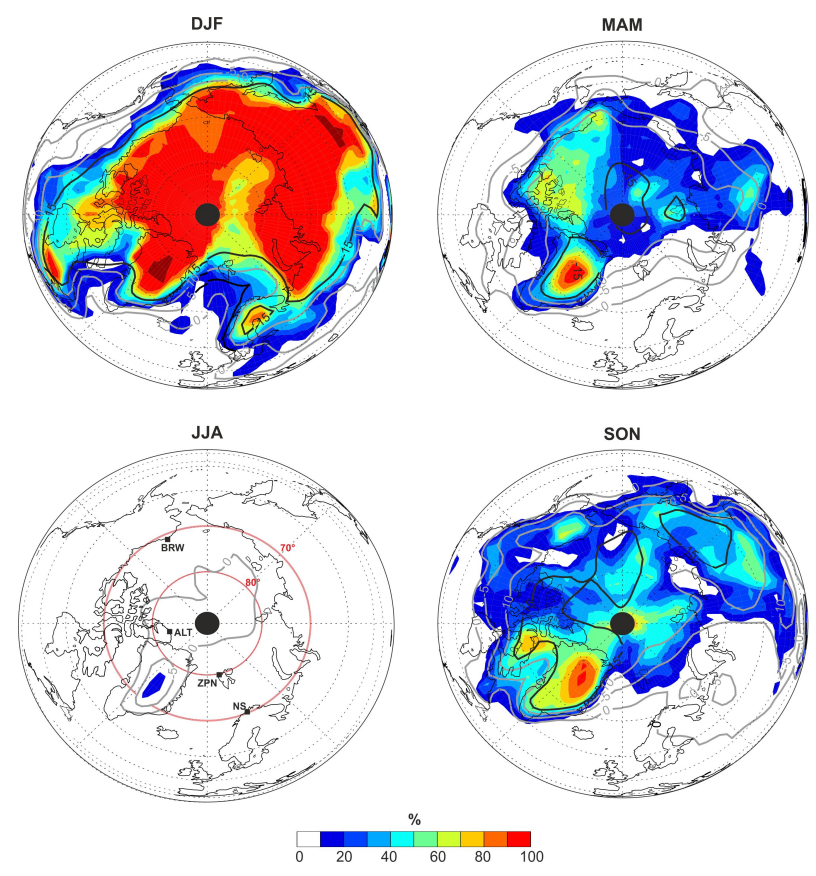

Fig. 4. Percentage of seasonal (DJF, MAM, JJA and SON) mean precipitation in an atmospheric column $\left(\mathrm{kg} \mathrm{m}^{-2} \mathrm{~d}^{-1}\right)$ formed at temperatures below $-15^{\circ} \mathrm{C}$ and so identified in GLOMAP-mode as snow. Also shown are the surface $-15^{\circ} \mathrm{C}$ (black solid line), $-10^{\circ} \mathrm{C},-5^{\circ} \mathrm{C}$ and $0{ }^{\circ} \mathrm{C}$ (grey solid lines as labelled) isotherms. In the bottom left-hand figure the positions of three Arctic groundstations: Alert (ALT), Barrow (BRW) and Zeppelin mountain (ZPN) are shown as is the approximate position of three closely located Northern Scandinavian sites: Oulanka, Karasjok and Janiskoski (NS).

layer and, although it is not the dominant wet removal process on a global scale, it is likely to be an important scavenging process in regions such as the Arctic which have limited frontal and convective rainfall (Curry et al., 1996; Hobbs and Rangno, 1998; Hobbs et al., 2001; Lawson et al., 2001; Gayet et al., 2009a).

To address this model deficiency a low-cloud scavenging scheme was added to the model. Low-cloud drizzle is assumed to occur in grid-boxes without convective or frontal rainfall and with a low-cloud fraction greater than zero (see Fig. 3). The CCN lifetime is assumed to be equal to the condensate lifetime, which is calculated using the methodology of Wood (2005):

$$
\tau_{\text {driz }}=\frac{L W P}{R_{\text {driz }}}
$$

where LWP is the low-cloud liquid water path $\left(\mathrm{kg} \mathrm{m}^{-2}\right)$ and $R_{\text {driz }}$ is the drizzle rate at cloud base $\left(\mathrm{kg} \mathrm{m}^{-2} \mathrm{~s}^{-1}\right)$. This removal rate is applied to a fraction of the $\mathrm{CCN}$ in each grid box according to the low cloud fraction (Sect. 4). We assume that the drizzle does not evaporate, thus our CCN scavenging rates are an upper limit for the given condensate lifetime.
Low cloud drizzle rates and LWP over mid-latitude and tropical regions were specified in the model based on observations from satellite climatologies (Leon et al., 2008) and are described fully in Table 2. In the Arctic, while measurements of LWP are documented in the literature, observations of low-cloud precipitation rates are to the best knowledge of the authors not available. Arctic drizzle rates were therefore estimated using the empirical relationship between cloud thickness $(z)$ and cloud droplet number concentration $\left(N_{\mathrm{d}}\right)$ observed by van Zanten and Stevens (2005) and calculated using the methodology of Wood (2006), such that

$R_{\text {driz }}=\frac{K_{\mathrm{VZ}} z^{3}}{N_{\mathrm{d}}}$,

where $K_{\mathrm{VZ}}=1.9 \times 10^{-5} \mathrm{~kg} \mathrm{~m}^{-8} \mathrm{~s}^{-1}$ is an empirically derived constant. This empirical relationship between drizzle rates and stratocumulus cloud properties was based on observations of nocturnal marine stratocumulus clouds off the Californian coast (van Zanten et al., 2005) and evaluated against observations off the European coast (Wood, 2005) and over the North Atlantic (Pawlowska, 2003). Derived drizzle rates were found to correlate strongly with observations $(R=0.97$ and 0.79 , respectively), although estimated N. Atlantic drizzle rates were biased low against observations $(-79 \%)$.

Analysis of observations over the Beaufort Sea $\left(70-76^{\circ} \mathrm{N}\right.$, $124-127^{\circ} \mathrm{W}$ ) of summertime Arctic cloud thickness and drop concentration in precipitating low-cloud (Hobbs and Rangno, 1998) yield a summertime Arctic drizzle rate of $0.44 \mathrm{~kg} \mathrm{~m}^{-2} \mathrm{~d}^{-1}$. In spring no precipitating clouds were observed but an average cloud droplet number of $73 \mathrm{~cm}^{-3}$ was calculated in low clouds with a non-trivial liquid water path. In conjunction with data from Hobbs et al. (2001), which suggest an average cloud depth of $150 \mathrm{~m}$ in the Arctic springtime boundary layer, these observations yielded a low cloud springtime drizzle rate of $0.08 \mathrm{~kg} \mathrm{~m}^{-2} \mathrm{~d}^{-1}$ albeit with a high degree of uncertainty.

Arctic drizzle rates calculated using Eq. (3) (scaled with mean low cloud fraction of 80-90\%) compare reasonably well to averaged precipitation measurements at Barter Island $\left(70^{\circ} \mathrm{N}, 143^{\circ} \mathrm{W}\right)$ and Barrow of $0.6 \mathrm{~kg} \mathrm{~m}^{-2} \mathrm{~d}^{-1}$ in summer and $0.08 \mathrm{~kg} \mathrm{~m}^{-2} \mathrm{~d}^{-1}$ in spring (Curtis et al., 1998) assuming that the majority of measured precipitation is drizzle. However at northern European sites measured precipitation rates are higher than those calculated $\left(0.3-1.0 \mathrm{~kg} \mathrm{~m}^{-2} \mathrm{~d}^{-1}\right.$ in spring and $1.7-2.0 \mathrm{~kg} \mathrm{~m}^{-2} \mathrm{~d}^{-1}$ in summer). It is unlikely that all of the precipitation measured is drizzle. Thus, the spring and summer drizzle rate in the European Arctic (defined in Table 2) was changed to $0.42 \mathrm{~kg} \mathrm{~m}^{-2} \mathrm{~d}^{-1}$ and $0.8 \mathrm{~kg} \mathrm{~m}^{-2} \mathrm{~d}^{-1}$, respectively. The effect of this increase on CCN grid-box lifetime is shown in Fig. 5.

Table 2 summarizes the modelled and observed drizzle rates and LWP in the stratocumulus zones (used to calculate in-cloud CCN lifetime as in Eq. 2). Figure 5 shows the grid-box CCN lifetime with respect to drizzle scavenging (incloud $\mathrm{CCN}$ lifetime divided by low cloud fraction). Outside 

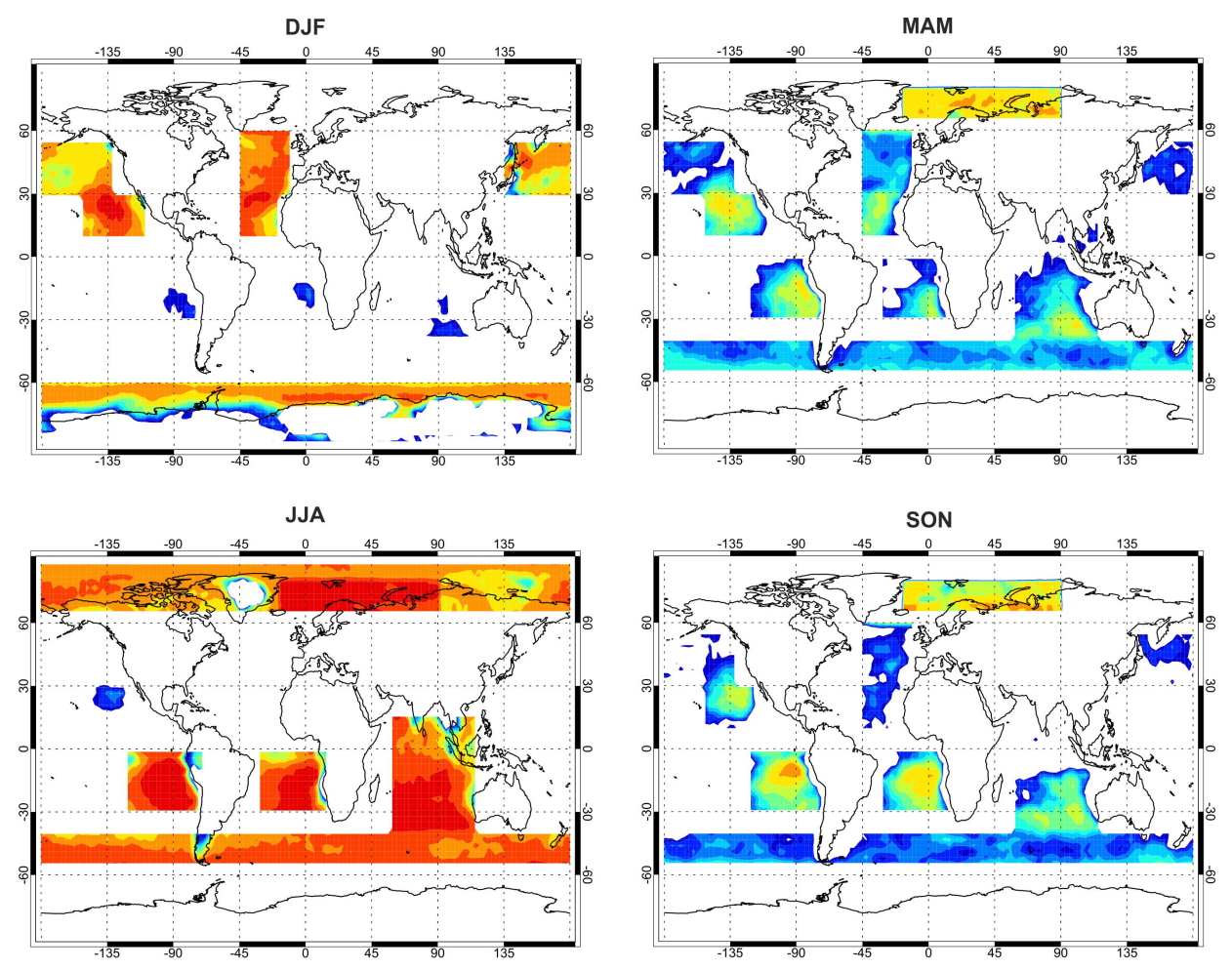

hours

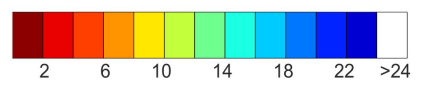

Fig. 5. Comparison of the CCN grid-box lifetime with respect to low cloud drizzle scavenging. Note that the colour scale is reversed from that in previous figures with red denoting a shorter $\mathrm{CCN}$ lifetime.

the main stratocumulus zones the minimum grid-box $\mathrm{CCN}$ lifetime is greater than $24 \mathrm{~h}$ and in most regions exceeds 4 days. Although Arctic drizzle rates are lower than in any other stratocumulus zones (Table 2), the higher low-cloud fraction introduced north of $60^{\circ} \mathrm{N}$ results in shorter average Arctic CCN grid-box lifetime from June-August (of 2-6h) equivalent to that in the southern ocean stratocumulus zone.

The importance of the drizzle rate to the scavenging efficiency in stratocumulus zones is discussed below in several sensitivity experiment.

\section{Description of model experiments}

Five sets of model simulations were completed to determine the importance of ice and low cloud scavenging processes for Arctic aerosol concentrations. All five simulations use identical meteorological fields and emission inventories and were spun up for 3 months (October-December 1999) before the beginning of each 3-yr period (2000-2002). The simulations are described below and summarized in Table 1:
- CTRL-ISCCP: a control run using global ISCCP low cloud climatologies including convective and frontal rain scavenging but without low-cloud precipitation. Scavenging of soluble aerosol is permitted to occur in both warm-phase and ice-phase clouds (see Fig. 3). This run uses the same set-up as Mann et al. (2010).

- CTRL-MODIS: a control run using the merged MODIS/ISCCP low-cloud climatologies as described in Sect. 4. Convective and frontal rain scavenging processes are identical to CTRL-ISCCP and low-cloud precipitation is likewise excluded. The merged cloud fields will be used in the remainder of the simulations, so this simulation provides a new baseline in place of CTRLISCCP.

- DRIZZ: this is the same as CTRL-MODIS except that low-cloud drizzle scavenging in the Arctic and stratocumulus cloud zones is permitted (as described in Sect. 5.2) with the restrictions outlined in Fig. 3. Convective and frontal rain scavenging processes remain identical to both CTRL-ISCCP and CTRL-MODIS. 
Table 1. Description of core simulations. Included cloud scavenging processes in each simulation are marked with an X.

\begin{tabular}{llcccc}
\hline Run Name & $\begin{array}{l}\text { low cloud } \\
\text { climatology }\end{array}$ & low cloud & $\begin{array}{c}\text { convective and } \\
\text { frontal cloud }\end{array}$ & $\begin{array}{c}\text { ice-cloud } \\
\text { (frontal and convective) }\end{array}$ & $\begin{array}{c}\text { ice-cloud } \\
\text { (low) }\end{array}$ \\
\hline CTRL-ISCCP & ISCCP & - & $\mathrm{X}$ & - & - \\
CTRL-MODIS & ISCCP/MODIS & - & $\mathrm{X}$ & - & - \\
DRIZZ & ISCCP/MODIS & $\mathrm{X}$ & $\mathrm{X}$ & - & - \\
ICE & ISCCP/MODIS & - & $\mathrm{X}$ & $\mathrm{X}$ & - \\
DRIZZICE & ISCCP/MODIS & $\mathrm{X}$ & $\mathrm{X}$ & $\mathrm{X}$ & $\mathrm{X}$ \\
\hline
\end{tabular}

Table 2. Drizzle rate $\left(\mathrm{kg} \mathrm{m}^{-2} \mathrm{~d}^{-1}\right)$ and cloud liquid water path $\left(\mathrm{g} \mathrm{m}^{-2}\right)$ in 11 stratocumulus zones used in drizzle parametrisation sourced from Leon et al. (2008) as observations (obs) or calculated from cloud characteristics (estimated).

\begin{tabular}{|c|c|c|c|c|c|c|c|c|}
\hline Region & $\begin{array}{r}\text { Winter } \\
\mathrm{kg} \mathrm{m}^{-2} \mathrm{~d}^{-1}\end{array}$ & $\begin{array}{r}\text { Spring } \\
\mathrm{kg} \mathrm{m}^{-2} \mathrm{~d}^{-1}\end{array}$ & $\begin{array}{r}\text { Summer } \\
\mathrm{kg} \mathrm{m}^{-2} \mathrm{~d}^{-1}\end{array}$ & $\begin{array}{r}\text { Autumn } \\
\mathrm{kg} \mathrm{m}^{-2} \mathrm{~d}^{-1}\end{array}$ & $\begin{array}{r}\text { LWP } \\
\mathrm{g} \mathrm{m}^{-2}\end{array}$ & $\begin{array}{l}\text { source } \\
R_{\text {driz }} / \mathrm{LWP}\end{array}$ & Latitude & Longitude \\
\hline N.Atlantic & 2.8 & 0.8 & 0.29 & 0.8 & 144 & obs /obs & $30-60^{\circ} \mathrm{N}$ & $10-45^{\circ} \mathrm{W}$ \\
\hline N.pacific & 2.3 & 0.68 & 0.29 & 0.68 & 131 & obs/obs & $30-55^{\circ} \mathrm{N}$ & $130^{\circ} \mathrm{W}-105^{\circ} \mathrm{E}$ \\
\hline Australian & 2.3 & 0.57 & 0.26 & 0.57 & 90 & obs/obs & $40^{\circ} \mathrm{S}-15^{\circ} \mathrm{N}$ & $60-115^{\circ} \mathrm{E}$ \\
\hline Circumpolar & 2.5 & 0.74 & 0.28 & 0.74 & 150 & obs/obs & $55-40^{\circ} \mathrm{S}$ & $180^{\circ} \mathrm{E}-180^{\circ} \mathrm{W}$ \\
\hline Nambian & 1.7 & 0.55 & 0.24 & 0.55 & 84 & obs/obs & $0-30^{\circ} \mathrm{S}$ & $30^{\circ} \mathrm{W}-15^{\circ} \mathrm{E}$ \\
\hline Canarian & 2.1 & 0.61 & 0.25 & 0.61 & 77 & obs/obs & $10-30^{\circ} \mathrm{N}$ & $45-20^{\circ} \mathrm{W}$ \\
\hline Peruvian & 1.9 & 0.6 & 0.26 & 0.6 & 91 & obs/obs & $0-30^{\circ} \mathrm{S}$ & $70-120^{\circ} \mathrm{W}$ \\
\hline Californian & 1.9 & 0.57 & 0.25 & 0.57 & 90 & obs/obs & $10-30^{\circ} \mathrm{N}$ & $110-150^{\circ} \mathrm{W}$ \\
\hline Arctic & 0.0 & 0.08 & 0.42 & 0.08 & 68 & estimated/obs & $60-90^{\circ} \mathrm{N}$ & $180^{\circ} \mathrm{E}-180^{\circ} \mathrm{W}$ \\
\hline Euro Arctic & 0.0 & 0.42 & 0.8 & 0.42 & 68 & estimated/obs & $60-80^{\circ} \mathrm{N}$ & $15^{\circ} \mathrm{E}-150^{\circ} \mathrm{W}$ \\
\hline Antarctic & 0.0 & 0.08 & 0.42 & 0.08 & 68 & Arctic values used & $60-90^{\circ} \mathrm{S}$ & $180^{\circ} \mathrm{E}-180^{\circ} \mathrm{W}$ \\
\hline
\end{tabular}

- ICE: this is the same as the CTRL-MODIS run except that ice-cloud scavenging of soluble aerosol is prohibited at temperatures less than $-15^{\circ} \mathrm{C}$. As in CTRLMODIS low clouds do not precipitate, the ice-cloud effect is applied to convective and frontal rain-clouds only.

- DRIZZICE: a combination of the DRIZZ and ICE runs, which includes merged MODIS and ISCCP low-cloud climatologies parameterisation of low-cloud drizzle in the Arctic and stratocumulus zones. To represent the slow removal rate in ice-phase clouds, scavenging of soluble aerosol is prohibited at $T<-15^{\circ} \mathrm{C}$ in low, frontal and convective clouds.

\section{Results and discussion}

\subsection{Control runs}

We first compare $\mathrm{SO}_{4}$ and $\mathrm{BC}$ concentrations in the two control runs using different high latitude low-cloud climatologies, CTRL-ISCCP and CTRL-MODIS (Fig. 6). In these runs the only effect of the low-level (non-drizzling) clouds is on $\mathrm{SO}_{4}$ production due to in-cloud oxidation and the growth of aerosol by aqueous phase reactions in non-precipitating clouds or cloud processing (Mann et al., 2010).
Predicted Arctic surface concentrations of $\mathrm{BC}$ mass are similar in CTRL-MODIS and CTRL-ISCCP throughout the year although the lower quartile from 60 to $90^{\circ} \mathrm{N}$ from December to February is typically lower in CTRL-MODIS (Fig. 6c). Likewise surface concentrations of $\mathrm{SO}_{4}$ are typically lower north of $60^{\circ}$ in CTRL-MODIS compared with CTRL-ISCCP (Fig. 6a). This mass decrease is the result of an increase in the rate of model cloud processing which counterintuitively decreases aerosol mass concentrations by decreasing $\mathrm{SO}_{4}$ and $\mathrm{BC}$ aerosol lifetime with respect to wet deposition (through changes in the aerosol size distribution).

Compared with surface observations, both control runs predict the seasonal $\mathrm{SO}_{4}$ mass concentration variation poorly. At Karasjok, Oulanka and Janiskoski (Fig. 7d), where observations show no seasonal variation in $\mathrm{SO}_{4}$ mass concentrations, both control runs have a summertime maximum that is up to a factor 10 greater than observed. At all three stations $\mathrm{SO}_{4}$ mass increases slightly with the use of MODIS cloud climatologies. This increase is small in the summer but is significant in the early winter $(40-50 \%)$ and stems from a greater $\mathrm{SO}_{2}$ oxidation to $\mathrm{SO}_{4}$ flux (100-200\%) in the vicinity of Finland and Northern Norway, which mitigates the regional wet deposition resulting from increases in cloud processing.

At Alert, Barrow and Zeppelin the $\mathrm{SO}_{4}$ mass concentration seasonal maximum occurs in early summer and is 3-4 months out of phase with the observations (Fig. $7 \mathrm{a}-\mathrm{c}$ ). In 


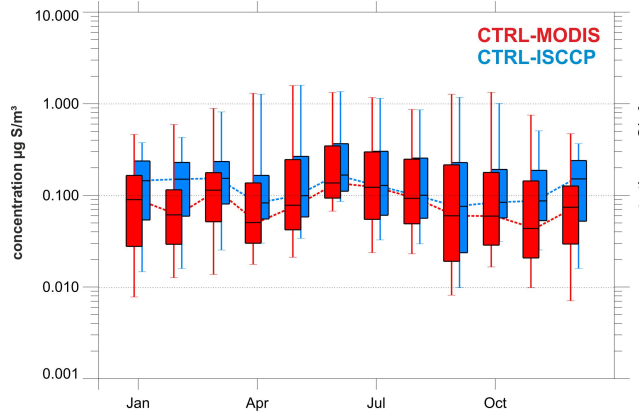

(a) $\mathrm{SO}_{4}$ mass concentration (control runs)

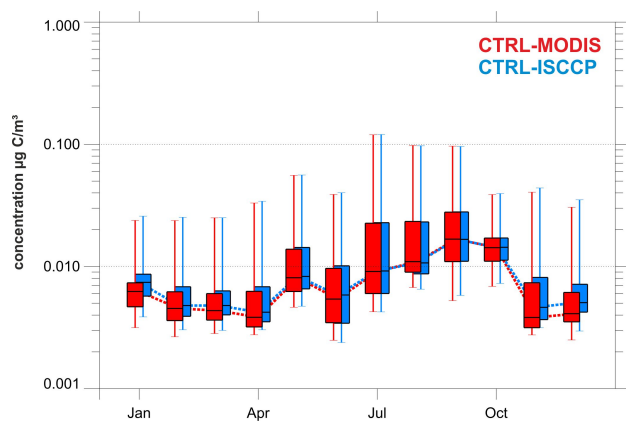

(c) BC mass concentration (control runs)

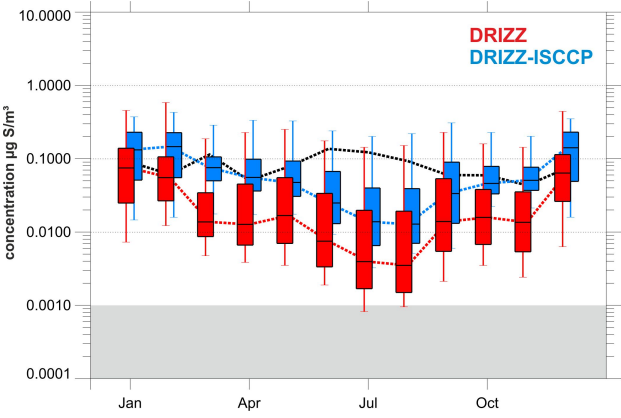

(b) $\mathrm{SO}_{4}$ mass concentration (drizzle runs)

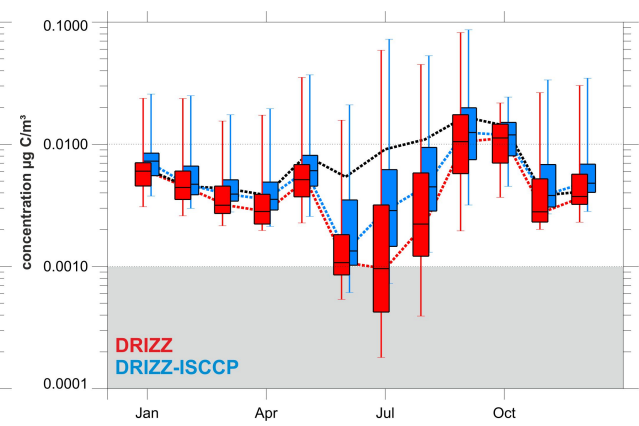

(d) BC mass concentrations(drizzle runs)

Fig. 6. Comparison of median and interquartile range $\mathrm{SO}_{4}(\mathbf{a}, \mathbf{b})$ and $\mathrm{BC}(\mathbf{c}, \mathbf{d})$ surface mass concentration (in the year 2000) between $60^{\circ}$ and $90^{\circ} \mathrm{N}$ for control runs CTRL-MODIS (red) and CTRL-ISCCP (blue) and drizzle runs DRIZZ (red) and DRIZZ-ISCCP (blue). The Errors bar denote the 5th and 95th percentiles in each month. Note: the ISCCP simulation results have been offset along the $\mathrm{x}$-axis, this was done to maintain clarity and does not indicate any difference in temporal resolution. In (c-d) the median $\mathrm{SO}_{4}$ and $\mathrm{BC}$ surface mass concentration in the CTRL-MODIS simulation are also shown (black dashed lines).

summer, $\mathrm{SO}_{4}$ mass concentrations at Alert and Barrow fall within one standard deviation of the observed mean, but at Zeppelin simulated $\mathrm{SO}_{4}$ concentrations from June to August are up to 4 times greater than measured. In winter modelled $\mathrm{SO}_{4}$ concentrations at Alert and Barrow are more than 2 standard deviations from the observational mean while at Zeppelin the model is less than 0.1 standard deviations from the observation mean (see Table 4).

The model prediction of $\mathrm{BC}$ mass concentrations and $\mathrm{EBC}$ data at Alert and Barrow is worse than for $\mathrm{SO}_{4}$ (Fig. $7 \mathrm{e}-\mathrm{f}$ ). The model is about 6 months out of phase, with a significant over-prediction in summer (a factor of $2.3 \sigma$ from the observation JJA mean at Barrow) and under-prediction in winter. The simulated summer BC maximum at both sites is skewed by anomalously high concentrations in August 2001. This maximum is due to the monthly updated GFED biomass burning (BB) emission inventories used in GLOMAP-mode. The monthly emission inventories assume a constant emission rate over the month. This assumption emphasises the contribution of forest fires which occur when meteorological conditions (which are updated every $15 \mathrm{~min}$ ) suppress the transport of BB emissions to ground-station sites. The overestimation of BB aerosol concentrations at these sites could be reduced by using daily resolved wildfire emission invento- ries in the model, however no such inventories were available to the authors pre-2008.

In summary, irrespective of the cloud climatology used, GLOMAP-mode fails to simulate the observed seasonal cycle, with insufficient $\mathrm{BC}$ and $\mathrm{SO}_{4}$ mass in the winter and early spring but too much $\mathrm{BC}$ and $\mathrm{SO}_{4}$ in the summer. The use of MODIS climatologies north of $60^{\circ}$ has had a negligible effect on modelled $\mathrm{SO}_{4}$ and $\mathrm{BC}$ surface mass concentration. However, the use of a different low-cloud climatology is likely to be of greater impact in simulations with low-cloud scavenging included, which we address below.

\subsection{Simulation DRIZZ}

\subsubsection{Effect of drizzle scavenging at the Arctic sites}

Scavenging due to drizzle reduces $\mathrm{SO}_{4}$ aerosol concentrations at all Arctic sites between March and November, with the greatest effect occurring in summer when Arctic drizzle rates are at a maximum (Fig. 7). By disproportionately reducing summertime concentrations, drizzle scavenging goes some way to correcting the negative correlation across the seasonal cycle. At stations north of $70^{\circ} \mathrm{N}$ the $\mathrm{R}$ correlation coefficient increases from -0.39 (CTRL-MODIS) to 0.47 


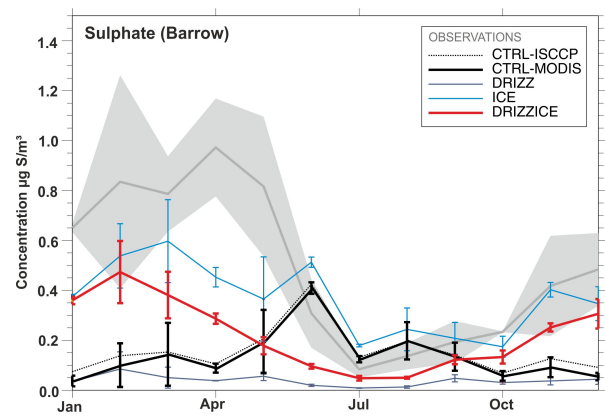

(a) Barrow $\left(71^{\circ} \mathrm{N}\right) \mathrm{SO}_{4}$

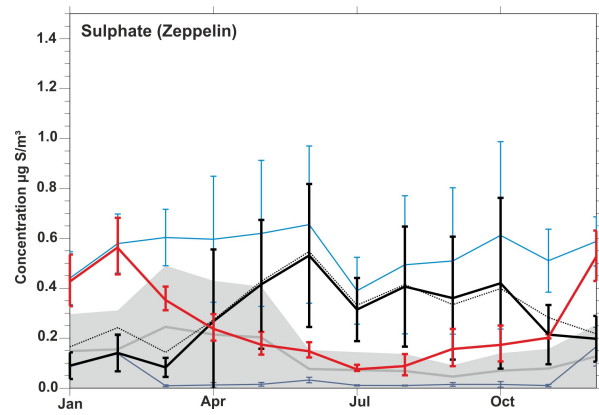

(c) Zeppelin $\left(79^{\circ} \mathrm{N}\right) \mathrm{SO}_{4}$

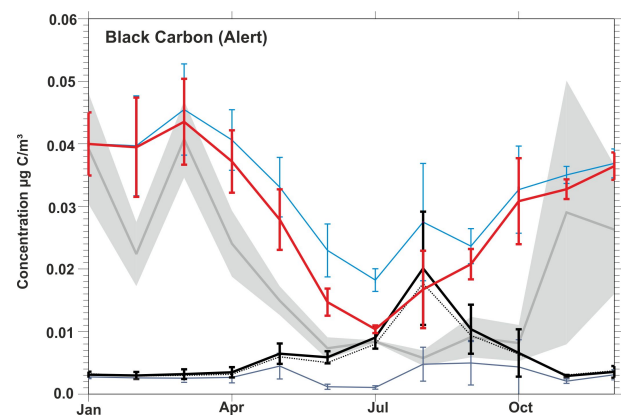

(e) Alert BC

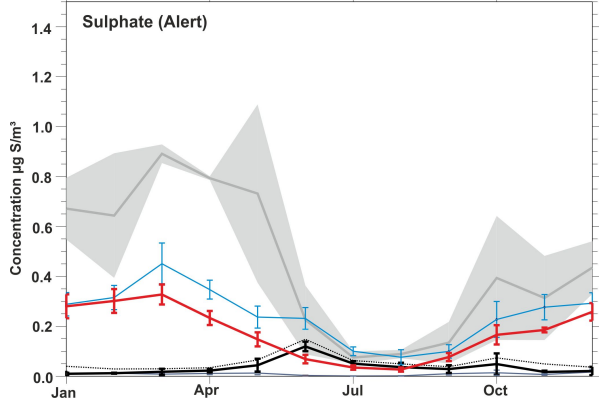

(b) Alert $\left(82^{\circ} \mathrm{N}\right) \mathrm{SO}_{4}$

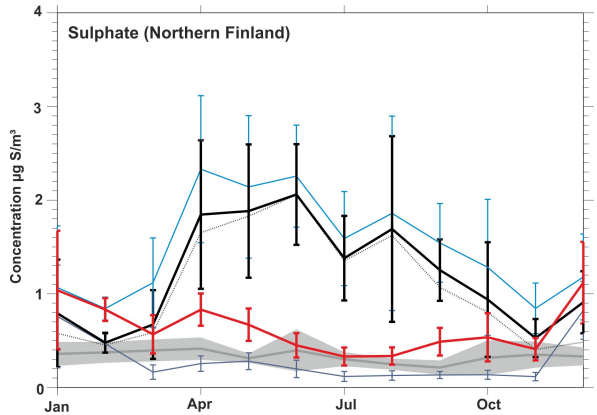

(d) EMEP stations $\left(66-69^{\circ} \mathrm{N}\right) \mathrm{SO}_{4}$

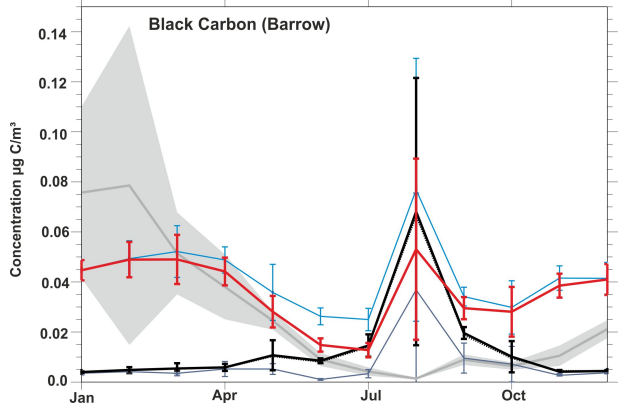

(f) Barrow BC

Fig. 7. Monthly mean $\mathrm{SO}_{4}$ and $\mathrm{BC}$ surface mass concentration at three Arctic ground-stations averaged over the model run period 20002002. Mass observations are shown in grey with the monthly inter-annual standard deviation indicated by light grey shading. Observed $\mathrm{SO}_{4}$ and $\mathrm{BC}$ mass concentrations are compared with both control runs (MODIS-black, ISCCP-black dashed), DRIZZ (dark blue), ICE (light blue) and DRIZZICE (red). Error bars represent the inter-annual standard deviation between yearly model runs. In (d) monthly $\mathrm{SO}_{4}$ mass concentration observations at the three EMEP stations (Karasjok, Janiskoski and Oulanka from 2000-2002) have been averaged and compared with modelled surface concentrations over Northern Norway and Finland (see Fig. 1).

(DRIZZ) at Alert, from -0.23 to 0.4 at Barrow and from -0.43 to 0.11 at Zeppelin. However, year-round drizzle also exacerbates the low model bias in winter, spring and autumn, increasing the annual mean negative bias to $-97 \%$ at Alert and to $-89 \%$ at Barrow (Table 3). At Zeppelin (Fig. 7c) drizzle scavenging has significantly decreased model bias, with $\mathrm{SO}_{4}$ concentrations annually underestimated by $60 \%$ in DRIZZ simulations.

At marginal Arctic sites (Karasjok, Janiskoski and Oulanka see Fig. 7d) modelled $\mathrm{SO}_{4}$ mass in DRIZZ is now on average less than one inter-annual standard deviation from observations $(-0.4,-0.1$ and -0.3 , respectively) and the model-observation bias is about -10 to $-20 \%$ (Table 3 ). Despite the consistent negative bias at all three stations the DRIZZ simulation is a considerable improvement on the average $200-300 \%$ positive bias in the control simulations. This analysis suggests that, while drizzle scavenging has very different effects on $\mathrm{SO}_{4}$ at the five Arctic sites, in general the effect of drizzle in the Arctic is to push modelled $\mathrm{SO}_{4}$ concentrations below observations.

Like $\mathrm{SO}_{4}$, Arctic $\mathrm{BC}$ mass concentrations have decreased in the DRIZZ simulation compared to CTRL-MODIS. At 
Barrow and Alert the correlation between observations and DRIZZ is still negative, as in CTRL-MODIS, but summer $\mathrm{BC}$ mass concentrations have decreased by a factor of $\sim 3$ in DRIZZ, reducing the average bias from $230 \%$ to $80 \%$. However, at Alert the negative model bias has increased in DRIZZ from $-40 \%$ to $-75 \%$ and summertime BC mass concentrations are now -1.4 standard deviations from the observation mean (Tables 3 and 4).

\subsubsection{How sensitive is Arctic aerosol to the Arctic drizzle rate?}

There are two significant uncertainties in our modelling of Arctic drizzle: the uncertainty in low-cloud cover (ISCCP versus MODIS) and the uncertainty in stratocumulus drizzle rates. The sensitivity of surface $\mathrm{SO}_{4}$ and $\mathrm{BC}$ concentrations to global drizzle rates was tested using four additional simulations: DRIZZx0.1 where global drizzle rates were decreased by a factor of 10 , DRIZZx0.5 where drizzle rates were decreased by a factor of 2, DRIZZx2 where drizzle rates were increased by a factor of 2 and DRIZZx 10 where drizzle rates were increased by a factor of 10 .

Changing global drizzle rates has a large effect on median surface $\mathrm{SO}_{4}$ mass concentrations north of $70^{\circ}$ (Fig. 8a). Halving drizzle rates increases Arctic surface $\mathrm{SO}_{4}$ concentrations from March to November by a factor of 2 and 3 (March-April and June-August, respectively) compared to DRIZZ simulations, while dividing drizzle rates by 10 increases summertime $\mathrm{SO}_{4}$ by a factor $\sim 10$. However, even with the very low scavenging rates in the DRIZZx0.1 simulations, $\mathrm{SO}_{4}$ concentrations are still a factor of 3 lower than in the CTRL-MODIS simulations without any drizzle. Thus, Arctic $\mathrm{SO}_{4}$ surface concentrations are highly sensitive to even very low drizzle rates.

Arctic surface $\mathrm{BC}$ concentrations are less sensitive to the drizzle rate than $\mathrm{SO}_{4}$, with median summertime concentrations above $70^{\circ} \mathrm{N}$ in DRIZZx0.1 increasing by a factor of $\sim 3$ compared to DRIZZ (Fig. 8b). The effect on the bias at Alert and Barrow is also negligible. In August all three drizzle runs have similar median $\mathrm{BC}$ concentration to the control (Sect. 7.1). The negligible effect of drizzle scavenging is confined to August and stems from a high fraction of hydrophobic $\mathrm{BC}$ in the Arctic $\mathrm{BC}$ load. Therefore, we suggest that $\mathrm{BC}$ concentrations during this month are sourced from biomass burning emissions (see Sect. 7.1) transported rapidly to the Arctic and unaffected by ageing processes (see Sect. 7.4 for further discussion).

We note that at Barrow and Alert the DRIZZx0.1 simulation is in much better agreement with observed summertime $\mathrm{SO}_{4}$ than the DRIZZ simulation (mean JJA bias reduced from $-93 \%$ to $-30 \%$ and from $-96 \%$ to $-56 \%$, respectively), but results in a large positive bias at the other sites (as in CTRL-MODIS). However, we do not draw conclusions about the best model simulation until we introduce the effect of reduced scavenging in ice clouds (Sect. 5.1). The question

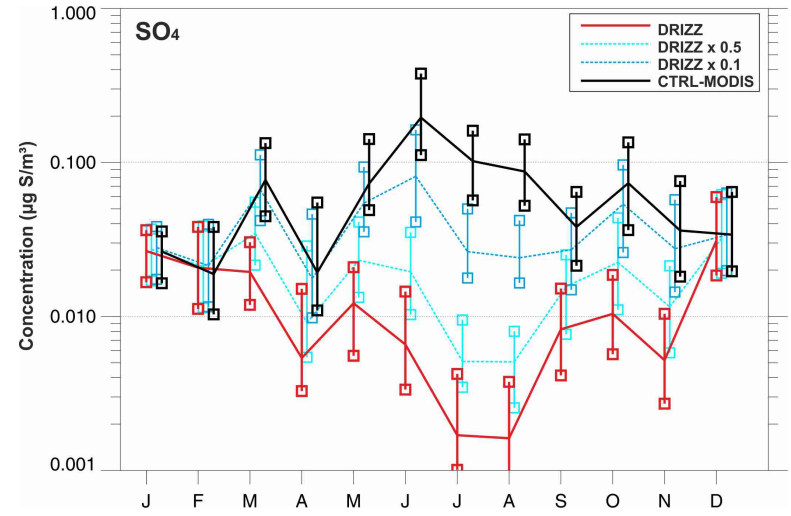

(a) Arctic $\mathrm{SO}_{4}$ mass concentration

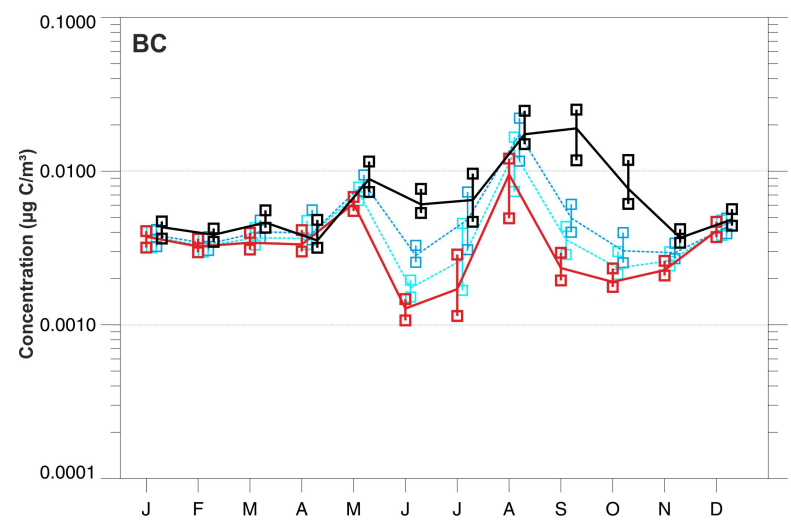

(b) Arctic BC mass concentration

Fig. 8. Median $\mathrm{SO}_{4}$ (a) and $\mathrm{BC}$ (b) mass concentration north of $70^{\circ}$ for CTRL-MODIS (black line), DRIZZ (red) and two drizzle sensitivity runs where global drizzle rates have been multiplied by 0.5 and 0.1 (blue dashed lines). Error bars represent the lower and upper quartile or the interquartile range. Note: all datasets have been offset from DRIZZ results along the $\mathrm{x}$-axis so that the figure remains clear but each represents the same time interval.

we now ask is from where this sensitivity to the drizzle rate arises: from changes to scavenging close to source regions in the extra-Arctic or local changes in the high-latitudes.

\subsubsection{Where does drizzle affect Arctic aerosol?}

The DRIZZ simulation includes drizzle scavenging globally, thus reductions in Arctic aerosol will be due to scavenging close to low-latitude sources, during transport from outside the Arctic, and at high latitudes. The relative effects of scavenging in these regions will likely vary with season and location because of seasonal variations in local and high latitude aerosol sources, cloud fractions, and precipitation rates. To determine the relative importance of drizzle north and south of $60^{\circ}$ we performed an additional model experiment in which drizzle occurs only between 0 and $60^{\circ}$.

We found that concentrations of $\mathrm{BC}$ and $\mathrm{SO}_{4}$ in this run differed negligibly from CTRL-MODIS at all six Arctic 
Table 3. Arctic Model-observation (ground-station) $R$ correlation and mean bias for CTRL-ISCCP, CTRL-MODIS, ICE, DRIZZ and DRIZZICE simulations from 2000 to 2002 (with the exception of Alert where no BC observations from 2001 where available).

\begin{tabular}{|c|c|c|c|c|c|c|c|c|c|c|c|}
\hline \multirow[t]{2}{*}{ site } & \multirow[t]{2}{*}{ species } & \multicolumn{2}{|c|}{ CTRL-ISCCP } & \multicolumn{2}{|c|}{ CTRL-MODIS } & \multicolumn{2}{|c|}{ DRIZZ } & \multicolumn{2}{|c|}{ ICE } & \multicolumn{2}{|c|}{ DRIZZICE } \\
\hline & & $R$ & bias $(\%)$ & $R$ & bias $(\%)$ & $R$ & bias $(\%)$ & $R$ & bias $(\%)$ & $R$ & bias (\%) \\
\hline Alert $(2000,2002)$ & $\mathrm{BC}$ & -0.68 & -43.7 & -0.69 & -39.8 & -0.29 & -74.58 & 0.65 & 92.7 & 0.72 & 58.95 \\
\hline Barrow & $\mathrm{BC}$ & -0.42 & 231.33 & -0.43 & 723.46 & -0.14 & 84.8 & 0.29 & 461.6 & 0.44 & 315.7 \\
\hline Zeppelin & $\mathrm{SO}_{4}$ & -0.42 & 306.8 & -0.43 & 288.2 & 0.11 & -61.9 & 0.03 & 530.2 & 0.4 & 149.7 \\
\hline Alert & $\mathrm{SO}_{4}$ & -0.33 & -67.6 & -0.39 & -76.2 & 0.47 & -97.1 & 0.72 & -18.4 & 0.71 & -52.1 \\
\hline Barrow & $\mathrm{SO}_{4}$ & -0.16 & -36.6 & -0.23 & -40.9 & 0.40 & -89.2 & 0.58 & 11.5 & 0.70 & -46.9 \\
\hline Karasjok & $\mathrm{SO}_{4}$ & 0.31 & 250.3 & 0.37 & 287.3 & 0.2 & -17.7 & 0.48 & 397.9 & 0.46 & 98.9 \\
\hline Oulanka & $\mathrm{SO}_{4}$ & 0.04 & 252.0 & 0.11 & 289.3 & 0.27 & -17.9 & 0.2 & 377.5 & 0.50 & 82.8 \\
\hline Janiskoski & $\mathrm{SO}_{4}$ & 0.43 & 188.4 & 0.47 & 222.9 & 0.12 & -8.6 & 0.51 & 305.6 & 0.27 & 82.7 \\
\hline
\end{tabular}

Table 4. Arctic model-observation error calculated as the mean difference between the model and observations divided by the standard deviation of the observed monthly mean at the ground-stations Alert, Barrow and Zeppelin. Data is shown averaged over the total time period 2000-2002 and for the DJF and JJA seasonal means.

\begin{tabular}{|c|c|c|c|c|c|c|c|c|c|c|c|c|c|c|c|}
\hline \multirow[t]{2}{*}{ simulation } & \multicolumn{3}{|c|}{ Alert (BC) } & \multicolumn{3}{|c|}{ Barrow (BC) } & \multicolumn{3}{|c|}{ Alert $\left(\mathrm{SO}_{4}\right)$} & \multicolumn{3}{|c|}{ Barrow $\left(\mathrm{SO}_{4}\right)$} & \multicolumn{3}{|c|}{ Zeppelin $\left(\mathrm{SO}_{4}\right)$} \\
\hline & tot & DJF & JJA & tot & DJF & JJA & tot & DJF & JJA & tot & $\mathrm{DJF}$ & JJA & tot & DJF & JJA \\
\hline CTRL-MODIS & -0.3 & -1.0 & 0.005 & 0.03 & -1.5 & 2.6 & -2.8 & -2.9 & -0.8 & -1.4 & -2.5 & 0.6 & 4.0 & -0.02 & 7.4 \\
\hline ICE & 1.8 & 0.02 & 0.9 & 1.8 & -0.05 & 4.0 & -0.7 & -1.3 & 1.2 & -0.07 & -0.9 & 1.3 & 8.1 & 5.4 & 9.7 \\
\hline DRIZZICE & 1.1 & 0.02 & 0.9 & 1.3 & -0.05 & 2.3 & -1.9 & -1.3 & -1.3 & -1.1 & -1.0 & -0.7 & 2.4 & 5.0 & 0.9 \\
\hline
\end{tabular}

ground stations. This result implies that drizzle at low latitudes $\left(<60^{\circ} \mathrm{N}\right)$ is unimportant for Arctic aerosol. That is, reduced aerosol concentrations in the extra-Arctic source regions are not the explanation for reductions in Arctic aerosol when drizzle is added to the model. This conclusion is further supported by the negligible change in $\mathrm{SO}_{4}$ and $\mathrm{BC}$ surface concentrations north of $60^{\circ}$ from December to February (when Arctic drizzle rates are set to 0) shown in Fig. 9a-b even after global drizzle rates are raised by a factor of 10 . Thus, any change in Arctic aerosol surface concentrations can be attributed to scavenging occurring at high latitudes.

We now address the question of where low-cloud scavenging occurs as aerosol is transported north of $60^{\circ}$. Figure $9 \mathrm{a}-\mathrm{b}$ shows the zonal mean surface $\mathrm{SO}_{4}$ and $\mathrm{BC}$ concentration for the simulations CTRL-MODIS, DRIZZ and all four drizzle rate sensitivity runs in the year 2002. Also shown is the effect of replacing the MODIS cloud climatologies with ISCCP at high latitudes.

In the Arctic summer the cumulative effect of drizzle scavenging causes a decrease in surface $\mathrm{SO}_{4}$ concentrations by an order of magnitude between the edge of the stratocumulus zone and $65^{\circ} \mathrm{N}$ (Fig. 9a). This decrease is in addition to the approximate factor 2 decrease due to other deposition processes (shown by the CTRL-MODIS black line). Thus drizzle is a dominant deposition process during this period. The effect on $\mathrm{BC}$ concentrations is less than for $\mathrm{SO}_{4}$, but mass concentrations are still reduced by an order of magnitude between 60 and $75^{\circ} \mathrm{N}$.
Figure 9a-b shows that increases in the summertime drizzle rate beyond those used in the DRIZZ simulations have a negligible additional effect because the rate is already very high. Halving the drizzle rate hardly affects the latitude at which $\mathrm{BC}$ and $\mathrm{SO}_{4}$ surface concentrations have fallen by an order of magnitude. However, the cumulative effect of the decreased drizzle rate is to approximately double $\mathrm{SO}_{4}$ and $\mathrm{BC}$ mass concentrations north of $80^{\circ}$. In DRIZZx 0.1 simulations, summertime zonal mass concentrations have increased by an order of magnitude compared to DRIZZ. Nevertheless, the average $\mathrm{CCN}$ boundary layer grid-box lifetime in these very low scavenging simulations is still $\sim 2$ days, and $\mathrm{SO}_{4}$ mass concentration still decrease by a factor of 3 below CTRLMODIS by $80^{\circ} \mathrm{N}$, and by a factor 10 taking into account all scavenging processes.

In addition Fig. 9c shows that substituting MODIS clouds with ISCCP reduces the scavenging and increases the $\mathrm{SO}_{4}$ concentrations at $75^{\circ} \mathrm{N}$ by about a factor of 2 . However, despite the large difference in cloud cover, the latitude by which aerosol concentrations have fallen by an order of magnitude remains approximately the same.

The overall effect of introducing drizzle is to improve the correlation of modelled and observed $\mathrm{SO}_{4}$ and $\mathrm{BC}$ concentrations at all sites (by suppressing spring-to-autumn concentrations more than winter), but it results in large negative biases. The underestimation of $\mathrm{SO}_{4}$ and $\mathrm{BC}$ mass concentrations north of $70^{\circ} \mathrm{N}$ may be caused by a too high Arctic low-cloud drizzle rates or result from our failure to account 


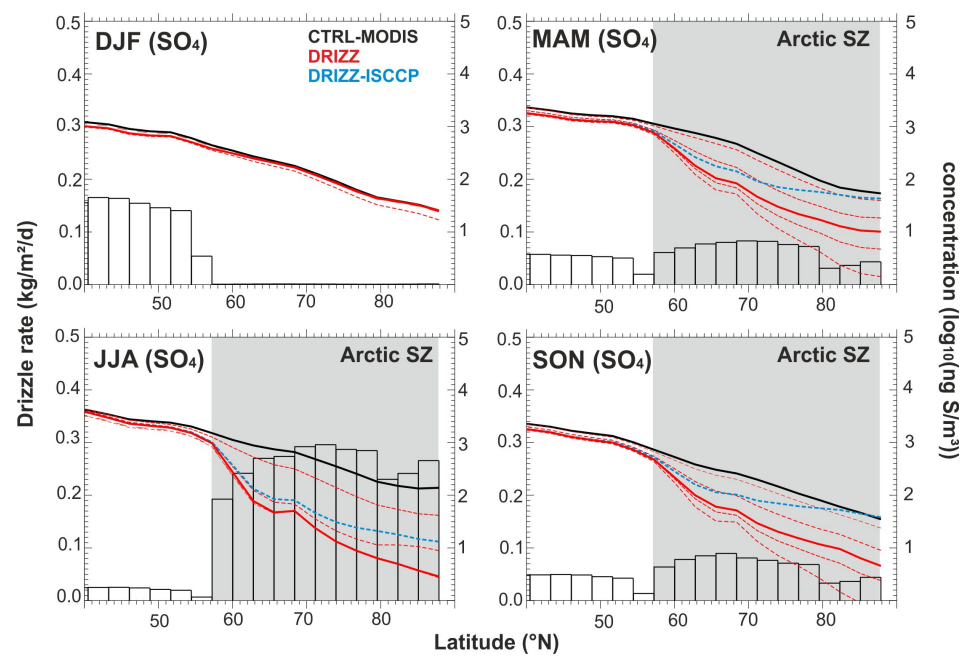

(a) Zonal mean surface $\mathrm{SO}_{4}$ concentration (2002)

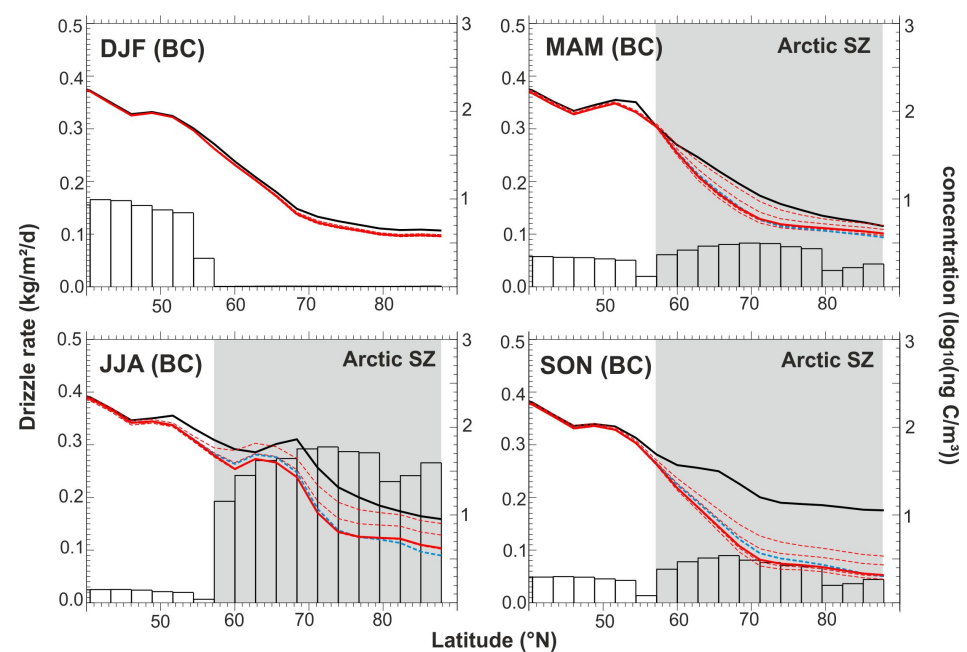

(b) Zonal mean surface BC concentration (2002)

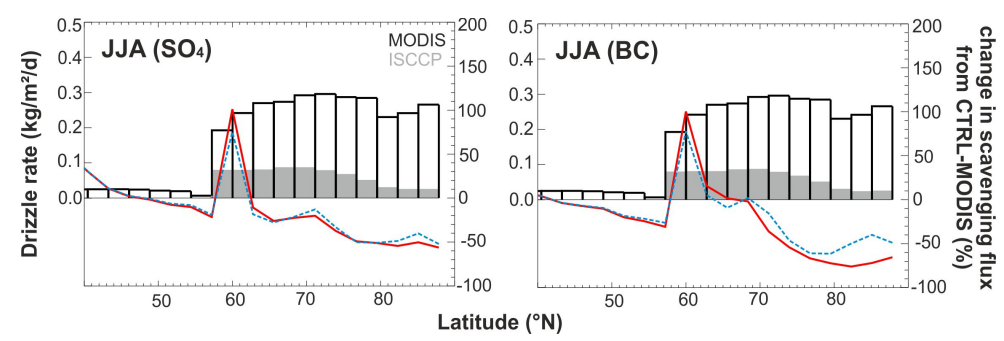

(c) Percentage change of zonal mean nucleation scavenging flux

Fig. 9. Histogram of zonal drizzle rate $\left.\left(\mathrm{kg} \mathrm{m}^{-2} \mathrm{~d}^{-1}\right)\right)$ compared with zonal $\mathrm{SO}_{4}(\mathbf{a})$ and $\mathrm{BC}(\mathbf{b})$ surface mass concentration $\left(\log _{10}\left(\mathrm{ng} X \mathrm{~m}^{-3}\right)\right.$ in CTRL-MODIS (black) and DRIZZ (red). In addition, also shown are results from four sensitivity studies where global drizzle rates have been homogeneously multiplied by $0.1,0.5,2.0$ and 10.0 (red dashed lines) and from the drizzle simulation DRIZZ-ISCCP which used ISCCP cloud climatologies north of $60^{\circ} \mathrm{N}$ (blue dashed line). Note: drizzle rates in (a) and (b) have been calculated using the merged MODIS and ISCCP cloud climatologies discussed in Sect. 4. (c) shows the JJA zonal drizzle rate calculated using both MODIS/ISCCP merged fields and ISCCP climatologies (gray) compared with the percentage change in the column integrated $\mathrm{SO}_{4}$ (left) and $\mathrm{BC}$ (right) nucleation scavenging rate from CTRL-MODIS in DRIZZ (red) and DRIZZ-ISCCP (blue) simulations. Grey shading indicates the latitudinal extent of the Arctic stratocumulus zone. 
for re-evaporation processes in drizzling clouds. However, sensitivity studies suggest that drizzle rates would need to decrease by a factor of 10 in order to agree with measurements at Alert and Barrow. This drastic reduction results in an overestimation of summertime $\mathrm{SO}_{4}$ mass concentrations at Zeppelin, Oulanka, Janiskoski and Karasjok.

Our analysis suggests that Arctic drizzling low cloud acts as a filter, strongly suppressing the transport of aerosol within the lower troposphere between the marginal $\left(60-70^{\circ} \mathrm{N}\right)$ and high $\left(70^{\circ} \mathrm{N}\right)$ Arctic. In addition, it is likely that the cloud layer acts to filter air vertically mixed down from the upper troposphere, reducing the effect of high altitude aerosol plumes (Warneke et al., 2010) on boundary layer concentrations. The spatial extent and efficiency of this filter is dependent on the imposed drizzle rate and stratocumulus boundary in the model as well as the height and thickness of the simulated cloud layer.

Although Arctic drizzle is an additional deposition process in the model, it is sufficiently rapid at the edge of the Arctic that net deposition of $\mathrm{SO}_{4}$ and $\mathrm{BC}$ is enhanced by drizzle only between about 60 and $70^{\circ} \mathrm{N}$, but decreased at higher latitudes (Fig. 9). This result suggests that the majority of aerosol transported into the Arctic boundary layer enters horizontally through the lower troposphere/boundary layer and is quickly deposited to the surface after vertical mixing into the cloud layer. In the next section we introduce a temperature threshold for all nucleation scavenging in GLOMAPmode.

\subsection{Simulation ICE}

\subsubsection{Effect of reduced ice scavenging}

The ICE run is based on CTRL-MODIS (i.e., no drizzle) but includes a complete suppression of scavenging of soluble aerosol below $-15^{\circ} \mathrm{C}$ (see Fig. 3). At Alert and Barrow (Fig. 7) this ice-cloud scavenging scheme has raised wintertime aerosol concentrations by up to a factor of 6 resulting in a $\mathrm{SO}_{4}$ and $\mathrm{BC}$ seasonal cycle that is in phase with observations. The $\mathrm{R}$ correlation between the model and $\mathrm{SO}_{4}$ observations has increased to 0.72 at Alert and to 0.58 at Barrow. The EBC $R$ correlation has increased to 0.65 at Alert and 0.29 at Barrow. In contrast, at Zeppelin ice-cloud scavenging, while increasing sulphate mass, has done little to correct the modelled seasonal cycle, reducing the $R$ correlation to 0.03 and increasing model bias from $300 \%$ to $530 \%$ (see Table 3).

At Karasjok, Janiskoski and Oulanka the effect of suppressed ice-cloud scavenging is much smaller than at the other sites, increasing $\mathrm{SO}_{4}$ by a few percent in summer and a maximum of a factor 2 in winter. These changes in $\mathrm{SO}_{4}$ aerosol at the different sites are broadly consistent with the column-mean fraction of ice cloud in the vicinity and southward of the sites. Alert and Barrow are well within the region of high ice-cloud occurrence in winter and even in spring and autumn (Fig. 4) while the other sites are only marginally
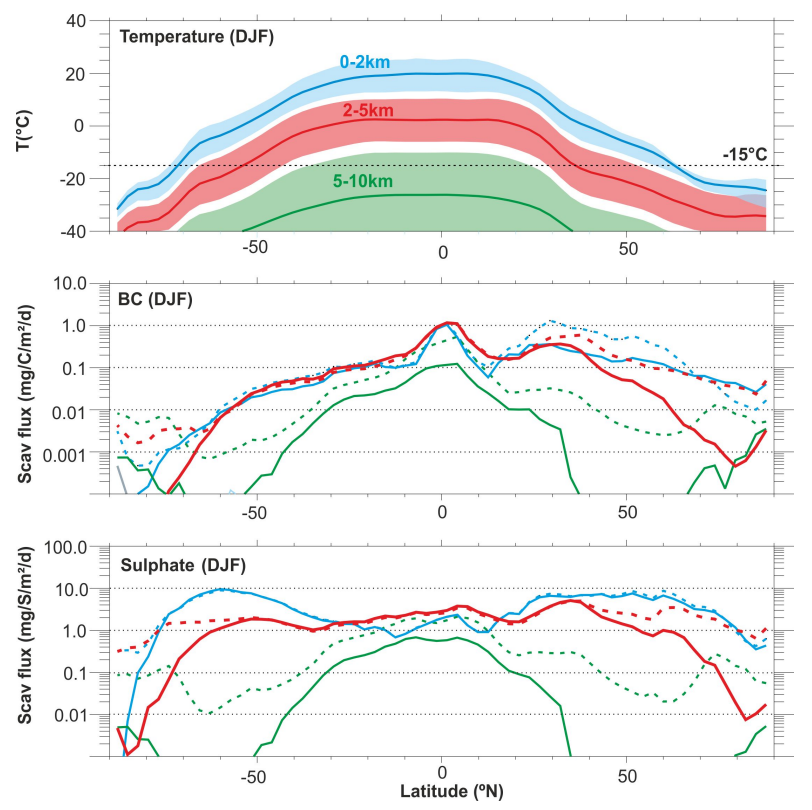

(a) scavenging flux (DJF)
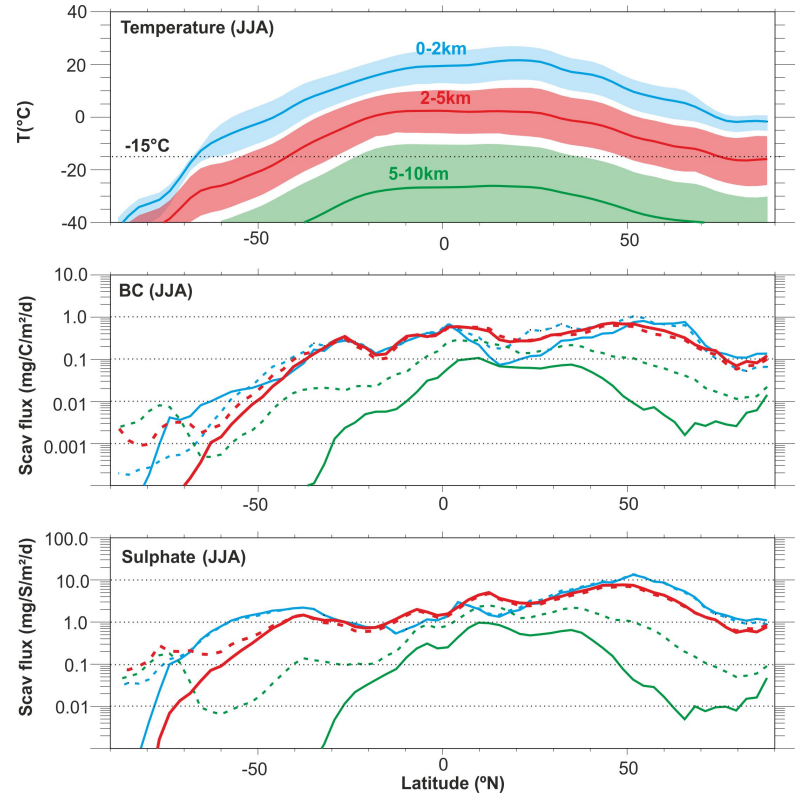

(b) scavenging flux (JJA)

Fig. 10. Zonal mean temperature (top) between $0-2 \mathrm{~km}$ (blue), 2-5 km (red) and 5-10 km (green) compared with BC (middle) and $\mathrm{SO}_{4}$ (bottom) zonal mean nucleation scavenging flux $\left(\mathrm{mg} X_{\mathrm{S}} \mathrm{m}^{-2} \mathrm{~d}^{-1}\right)$ in CTRL-MODIS (dashed line) and ICE (solid line) integrated between equivalent atmospheric regions. The shading in the zonal mean temperature plots indicates the minimum and maximum temperature in each atmospheric region. (a) shows analysis of the December-February seasonal mean while (b) shows analysis of the June-August mean. 
within this region in winter and well outside it in other seasons.

We can analyse the vertical profile of temperature and the column-integrated nucleation scavenging flux $\left(\mathrm{mg} \mathrm{m}^{-2} \mathrm{~d}^{-1}\right)$ to determine where the effect of the ice clouds is greatest. Figure 10 shows the zonal mean temperature and $\mathrm{SO}_{4}$ and $\mathrm{BC}$ integrated scavenging fluxes in CTRL-MODIS and ICE for the altitude levels $0-2 \mathrm{~km}$ (boundary/residual layer), $2-5 \mathrm{~km}$ (lower troposphere) and 5-10 km (mid-upper troposphere), the sum of which is equivalent to the deposition per $\mathrm{m}^{2}$ per day. In the ICE simulation, the wintertime $\mathrm{SO}_{4}$ scavenging flux decreases considerably above the boundary layer for latitudes greater than about $50^{\circ} \mathrm{N}$, corresponding to locations with mean temperatures below $-15^{\circ} \mathrm{C}$. In summer, the effect of the ice scavenging is evident only above $\sim 5 \mathrm{~km}$ altitude, and therefore has a minimal effect on surface level aerosol (Fig. 7).

In the wintertime boundary layer the $\mathrm{SO}_{4}$ scavenging rate does not significantly change between CTRL-MODIS and ICE, but falls substantially at higher altitudes. In contrast, boundary layer BC scavenging decreases by a factor $\sim 4$ between 30 and $60^{\circ} \mathrm{N}$ in the ICE simulation and increases by up to a factor 3 above $70^{\circ} \mathrm{N}$. This change in BC scavenging at temperatures where the ICE parameterisation ought to have a negligible effect is due to the response of the mixing state of the $\mathrm{BC}$ particles to changes in $\mathrm{SO}_{4}$. In CTRLMODIS the majority of $\mathrm{BC}$ mass in the Arctic is insoluble $(\sim 80 \%)$ and within the Aitken mode $(\sim 90 \%)$ while in the ICE simulation BC mass is predominantly soluble (70$90 \%$ ) and split evenly between the Aitken and accumulation modes. Therefore, annually a greater proportion of $\mathrm{BC}$ mass is scavengable in ICE then in CTRL-MODIS, resulting in an increase in $\mathrm{BC}$ scavenging rates above $70^{\circ} \mathrm{N}$. The ratio between Aitken mode and accumulation mode $\mathrm{SO}_{4}$ mass has also changed, with a greater proportion of boundary layer $\mathrm{SO}_{4}$ mass within the Aitken mode $(\sim 10 \%)$. However, this small decrease in accumulation mode mass has done little to alter the $\mathrm{SO}_{4}$ scavenging flux between 0 and $2 \mathrm{~km}$.

The shift in BC characteristics between CTRL-MODIS and ICE suggests that in ICE a greater proportion of Arctic $\mathrm{BC}$ aerosol is composed of aged particles transported from latitudes below $60^{\circ} \mathrm{N}$. While the increase in $\mathrm{SO}_{4}$ mass concentration at all stations coupled with a shift in $\mathrm{SO}_{4}$ particle size from the Aitken to the accumulation mode at $\sim 500 \mathrm{hPa}$ suggests an equivalent increase in $\mathrm{SO}_{4}$ transport from the extra-Arctic.

\subsubsection{Sensitivity to the ice threshold temperature}

The ice scavenging temperature threshold is very uncertain and is controlled by many processes that are not simulated in GLOMAP. To test the sensitivity of Arctic aerosol to this threshold, we performed three additional experiments in which the threshold temperature was changed to $-10,-5$ and $0^{\circ} \mathrm{C}$. Changing the ice-phase temperature threshold to $-10^{\circ} \mathrm{C}$ (ICE-10) and $-5^{\circ} \mathrm{C}$ (ICE-5) increased wintertime median $\mathrm{BC}$ concentrations north of $70^{\circ} \mathrm{N}$ by $8 \%$ and $25 \%$, respectively and $\mathrm{SO}_{4}$ concentrations by $35 \%$ and $66 \%$, respectively.

The relatively low sensitivity of winter surface aerosol concentrations to the ice-phase threshold is explained by the sharp meridional temperature gradient (Fig. 4). In late spring when the zonal temperature gradient is weaker, changing the ice-phase temperature threshold to $-10^{\circ} \mathrm{C}$ (ICE-10) and $-5^{\circ} \mathrm{C}$ (ICE-5) increases $\mathrm{SO}_{4}$ surface concentrations north of $70^{\circ} \mathrm{N}$ by $85 \%$ and $250 \%$, respectively and BC concentrations by $22 \%$ and $70 \%$, respectively. Comparison of the ICE-10 simulation with surface observations suggests that increasing the ice-phase temperature threshold has decreased model $\mathrm{SO}_{4}$ bias at Alert (from $-18 \%$ to $-2 \%$ ) and Zeppelin $\left(530 \%\right.$ to $463 \%$ ) but increased model $\mathrm{SO}_{4}$ bias at Barrow $(11 \%$ to $37 \%)$. At all other sites model bias has changed negligibly.

The non-uniform springtime response at different sites to increases in the ice-phase temperature threshold might change if mixed-phase scavenging processes were included. The scavenging efficiency of mixed-phase clouds is likely to be spatially variable due to variations in liquid-to-ice cloud ratios between regions (Smith et al., 2009). Thus, better treatment of mixed-phase cloud processes has the potential to improve the simulated spatial and temporal patterns of aerosol concentrations.

It is possible that by suppressing (or overestimating) scavenging rates in mixed-phase clouds during the spring we delay (or accelerate) the simulated transition from the Arctic late-spring haze period to the "clean" summer boundary layer. However, this effect is not evident in the majority of our ground-station comparisons (Fig. 7).

An unrealistic ice-phase threshold of $0{ }^{\circ} \mathrm{C}$ does result in a significant change in winter-early spring $\mathrm{BC}$ and $\mathrm{SO}_{4}$ mass, increasing concentrations by 50 and $100 \%$, respectively. However, the greatest effect on surface aerosol concentrations for this simulation occurs in summer where $\mathrm{SO}_{4}$ and $\mathrm{BC}$ concentrations increase by 550 and $120 \%$, respectively. This increase results in a modelled maximum at the majority of Arctic sites that is two months out of phase with observations.

In summary the suppression of soluble aerosol scavenging in ice-clouds increases concentrations of aged sulphate and $\mathrm{BC}$ aerosol in the Arctic boundary layer. Including this suppressed scavenging in the model corrects the negative bias of the model versus the observations in the winter and spring. However, in the summer the positive bias seen in CTRLMODIS has been exaggerated by the ice-cloud scavenging scheme. This is particularly evident at marginal Arctic sites. Sensitivity studies suggest that, in winter surface concentrations of $\mathrm{SO}_{4}$ and particularly $\mathrm{BC}$ are relatively insensitive to increases in the ice-phase temperature threshold of less then $5^{\circ} \mathrm{C}$. In the next section we show how a combination of suppressed wintertime ice-phase scavenging and enhanced 
summertime drizzle scavenging results in the correct seasonal cycle at both high latitude and marginal Arctic sites.

\subsection{Simulation DRIZZICE}

Simulation DRIZZICE includes the low-level cloud drizzle scavenging processes of DRIZZ and the suppressed ice-cloud scavenging of the ICE simulation (now applied to all clouds, including drizzling clouds). Section 7.2 showed that drizzle suppresses Arctic aerosol in all seasons (with a greater effect in summer because of the higher cloud coverage) but exacerbates the model low bias in winter. The ice scavenging process acts in the other direction by suppressing scavenging in winter. We now study the combined effect of DRIZZ and ICE.

A comparison of DRIZZICE and CTRL-MODIS with ground-station $\mathrm{SO}_{4}$ mass observations shows that the modelobservation correlation at Alert, Barrow and Zeppelin has increased from a negative coefficient at all stations in CTRLMODIS to $0.71,0.7$ and 0.4, respectively in DRIZZICE (Table 3). Thus, the combined effect of drizzle and suppressed scavenging in ice clouds has had the desired effect of decreasing summertime $\mathrm{SO}_{4}$ and increasing wintertime $\mathrm{SO}_{4}$ compared to CTRL-MODIS. The model captures the large seasonal cycle at the high latitude Arctic sites (Alert, Barrow and Zeppelin) and the weaker cycle at the marginal Arctic sites Karasjok, Oulanka and Janiskoski (Fig. 7).

For BC, the correlation coefficient has changed sign increasing from -0.7 (CTRL-MODIS) to 0.72 at Alert and from -0.43 to 0.44 at Barrow. The wintertime (DJF) bias in $\mathrm{BC}$ has reduced from $-94 \%$ to $2 \%$ at Barrow and $-92 \%$ to $-11 \%$ at Alert, and the model is within 0.1 standard deviations of the DJF observation mean at both sites. However, the annual mean model bias at both stations has increased from $70 \%$ in CTRL-MODIS to $200 \%$ in DRIZZICE at Barrow and from $-53 \%$ to $59 \%$ at Alert. This increase in model bias is due to the effect of ice-cloud scavenging in winter and spring (where the model negative bias has been reduced) combined with the inefficiency of drizzle scavenging on fresh Aitken mode $\mathrm{BC}$ which typically dominates the modelled summertime aerosol size distribution.

The dominance of insoluble Aitken mode BC in the late summer and early autumn over the Canadian and Siberian Arctic (70-90\% of the total BC mass) is the result of the ageing scheme used in GLOMAP. Aerosol in GLOMAP is aged by condensation of $\mathrm{SO}_{2}$. $\mathrm{BC}$ (and $\mathrm{OC}$ ) particles become hydrophilic when they have a sufficient coating of $\mathrm{SO}_{2}$, assumed here to be 10 monolayers of $\mathrm{H}_{2} \mathrm{SO}_{4}$. This is significantly higher than the previous threshold of 1 monolayer, and was altered to improve the model agreement with remote observations of BC (Mann et al., 2010). A similar decision was made by Liu et al. (2011) in their global model. However, in Liu et al. (2011) the required thickness of $\mathrm{H}_{2} \mathrm{SO}_{4}$ was explicitly calculated from the Köhler equations.
The effect of assuming that $\mathrm{BC}$ rapidly becomes soluble can be estimated from the dependence of $\mathrm{SO}_{4}$ on drizzle rates. In August, high latitude $\mathrm{SO}_{4}$ concentrations fall by a factor of 600 between runs CTRL-MODIS and DRIZZ and by a factor of 200 between runs CTRL-MODIS and DRIZZx0.5, while BC falls by a factor of 1.6 and 1.3 respectively (Fig. 8). Thus, assuming highly soluble BC would reduce $B C$ by a factor of $\sim 200$, simulated August BC concentrations would be in better agreement with observations at Alert and Barrow (Fig. 7). However, it is not known whether the overprediction of August high latitude BC is the result of inaccurate emissions or incorrect scavenging.

In conclusion, the use of both drizzle and ice-cloud scavenging schemes in GLOMAP-mode has significantly improved the Arctic model evaluation compared with both CTRL-ISCCP and CTRL-MODIS (Fig. 7 and Table 3). This analysis is clear evidence for two processes affecting surfacelevel aerosol: scavenging in the free troposphere before the aerosol is entrained into the boundary layer (which is controlled here by the change in ice scavenging), and scavenging within the boundary layer itself caused by low-level warm clouds. In the winter, Arctic aerosol is controlled mostly by the free tropospheric scavenging, which is reduced when ice forms, and in the summer is controlled less by scavenging in the free troposphere but by scavenging in low-level drizzling clouds which filter air transported north of $60^{\circ}$. These adjustments to the model have also affected aerosol concentrations outside the Arctic, which we briefly review below.

\subsection{Global impact of scavenging processes}

Previous comparisons of GLOMAP-mode with numerous aerosol datasets outside of the Arctic (Mann et al., 2010) show a good agreement between the control model and observations. We now show that inclusion of drizzle and icecloud scavenging effects leads to small improvements in the model elsewhere.

The DRIZZICE, ICE and DRIZZ simulations were compared with annual mean $\mathrm{SO}_{4}$ surface concentrations from the EMEP (26 stations), IMPROVE (12 stations), GAW (1 station) and the University of Miami ground-station networks (28 stations) and annual mean EBC surface concentrations from the IMPROVE network (12 stations) (Stier et al., 2005). The IMPROVE and EMEP networks are situated in N. America and Europe, respectively while stations in the University of Miami network range from urban (Miami at $80.2^{\circ} \mathrm{W}$ and $25.8^{\circ} \mathrm{N}$ ) to isolated sites (Palmer in Antarctic at $64^{\circ} \mathrm{W}$ and $64.8^{\circ} \mathrm{S}$ ) and include numerous island and coastal stations situated in or near modelled stratocumulus zones (Cook island, Reunion Island).

Comparison of the CTRL-MODIS simulation with all $\mathrm{SO}_{4}$ datasets concurs with the findings of Mann et al. (2010) that GLOMAP-mode predicts surface concentrations of $\mathrm{SO}_{4}$ well at all stations, with an average (over all networks) correlation coefficient of 0.88 and positive mean model bias of 
$74 \%$. Likewise, in both DRIZZ and DRIZZICE simulations the model-observation correlation is $\sim 0.8$, but the bias decreases to $32 \%$ in DRIZZ and $65 \%$ in DRIZZICE. The ICE simulation shows no significant change from the control.

Comparison with the few EBC surface mass concentrations in the IMPROVE network (12 sites) shows the modelobservation correlation in DRIZZICE has improved negligibly (from 0.32 to 0.35 ) and model bias has improved from $-37 \%$ (CTRL-MODIS) to $-21 \%$ (DRIZZICE). Similar analysis of ICE and DRIZZ with observations suggest that the decrease in BC model bias in DRIZZICE stems from the effect of ice-cloud scavenging rather than drizzle processes.

Global BC mass concentrations have increased in DRIZZICE particularly in the remote marine boundary layer (not shown here), despite the strong BC scavenging rates associated with the stratocumulus zones. In remote regions the increase in boundary layer $\mathrm{BC}$ concentrations in the DRIZZICE simulations stems from a number of contributing factors. Firstly, there is a significant decrease in BC particle size (from accumulation to Aitken mode) in the boundary layer in BC source regions such as Eastern Asia due to decreases in cloud processing of smaller to larger particles) which results in a decrease in $\mathrm{BC}$ scavenging in the lower troposphere. Secondly, the decrease in boundary layer $\mathrm{SO}_{4}$ in DRIZZICE results in a increase in the model BC ageing lifetime, which mitigates the increase in $\mathrm{BC}$ scavenging in DRIZZ simulations.

Although the percentage increase in $\mathrm{BC}$ concentrations in the southern hemisphere is large $(\sim 100 \%)$ the absolute increase is small due to the low concentrations of $\mathrm{BC}$ in this region (BC concentrations remain less than $0.01 \mu \mathrm{g} \mathrm{m}^{-3}$ ). However, in the Northern Hemisphere the increase in BC mass from CTRL-MODIS to DRIZZICE is significant, with $\mathrm{BC}$ concentrations in interior Russia rising from $\sim 0.01 \mu \mathrm{g} \mathrm{m}^{-3}$ to $0.1 \mu \mathrm{g} \mathrm{m}^{-3}$ in DRIZZICE and North Atlantic BC mass concentrations rising from $<0.02 \mu \mathrm{g} \mathrm{m}^{-3}$ in CTRL-MODIS to $0.05-0.07 \mu \mathrm{g} \mathrm{m}^{-3}$ in DRIZZICE.

$\mathrm{BC}$ mass concentration observations from a two-leg cruise in October 1992 from Nova Scotia to Morocco are available for comparison with modelled North Atlantic surface BC concentrations. The JGOFS 92-037 cruise measured a mean BC concentration of $0.024 \mu \mathrm{g} \mathrm{m}^{-3}$ over the central North Atlantic $\left(25-50^{\circ} \mathrm{W}\right)$ (Van Dingenen et al., 1995). The CTRLMODIS simulation predicts $0.015 \mu \mathrm{g} \mathrm{m}^{-3}$ in this region and $0.033 \mu \mathrm{g} \mathrm{m}^{-3}$ in the DRIZZICE simulation (correlation of 0.82 and bias of $55 \%$ versus the observations). However, conclusions about the validity of this global increase in BC mass concentrations remain tentative without more diverse observations.

In conclusion the simulation DRIZZICE compares as well (or better) with available $\mathrm{SO}_{4}$ and $\mathrm{BC}$ mass concentration observations outside of the Arctic.

\section{Conclusions}

We have used a global model of aerosol processes to investigate how scavenging processes control the seasonal variation of $\mathrm{SO}_{4}$ and $\mathrm{BC}$ aerosol in the Arctic. The effect of these scavenging processes was tested by comparing five model sensitivity simulations (Sect. 6) with surface observations of aerosol mass concentration at three independent Arctic ground-stations: Alert $\left(82.5^{\circ} \mathrm{N}\right)$, Zeppelin Mountain on Svalbard $\left(78.9^{\circ} \mathrm{N}\right)$ and Barrow $\left(71^{\circ} \mathrm{N}\right)$, and averaged observations from the closely situated Scandinavian/Russian stations Karasjok, Oulanka and Janiskoski which lie between $66-69^{\circ} \mathrm{N}$.

Inclusion of a new drizzle scavenging process and suppression of soluble aerosol scavenging in all clouds below $-15^{\circ} \mathrm{C}$ leads to a significant improvement in the agreement between the model and observations. In particular, the inverse seasonal cycle of aerosol concentration in the control run (with peak aerosol in the spring-summer) is corrected through a combination of these scavenging processes. The suppression of scavenging in ice clouds below $-15^{\circ} \mathrm{C}$ has the most pronounced effect, leading to a large increase in wintertime aerosol and reversing the modeled seasonal cycle.

The ice effect is most pronounced at the high latitude sites of Alert, Barrow and Zeppelin, leading to an average factor 6 increase in DJF $\mathrm{SO}_{4}$, with the effect extending from autumn to spring. The effect is much weaker (factor 2) at the Scandinavian/Russian sites and is restricted to the winter months. This difference in the effect of ice clouds is consistent with the location of the sites relative to the $-15^{\circ} \mathrm{C}$ isotherm, which lies asymmetrically over the pole (being shifted towards N. America and Asia, Fig. 4). The analysis suggests that the magnitude of the aerosol seasonal cycle is determined partly by the location of the site relative to the zone of lowest temperatures, with Barrow and Alert having the largest amplitude cycle, followed by Zeppelin, and the Finnish sites having a weak seasonal cycle. The seasonal cycle is further amplified by the occurrence of drizzle in lowlevel stratus clouds.

Our global 3-D model analysis is consistent with the observational analysis of Garrett et al. (2010), who identified a seasonal temperature "switch" controlling the distribution of Arctic aerosol mass. Here we have shown that the likelihood of a site exhibiting a characteristic Arctic aerosol seasonal cycle is dependent on its position relative to the winterspring $-15^{\circ} \mathrm{C}$ surface isotherm (see Fig. 4). Our approach of simply switching off scavenging below $-15^{\circ} \mathrm{C}$ is expedient in a model that does not simulate cloud microphysics. This threshold temperature may vary spatially and depend on the cloud and aerosol types, but the existence of some kind of threshold temperature is borne out by the Garrett et al. (2010) analysis and our model results, which also suggest that the precise temperature may not be very important. 


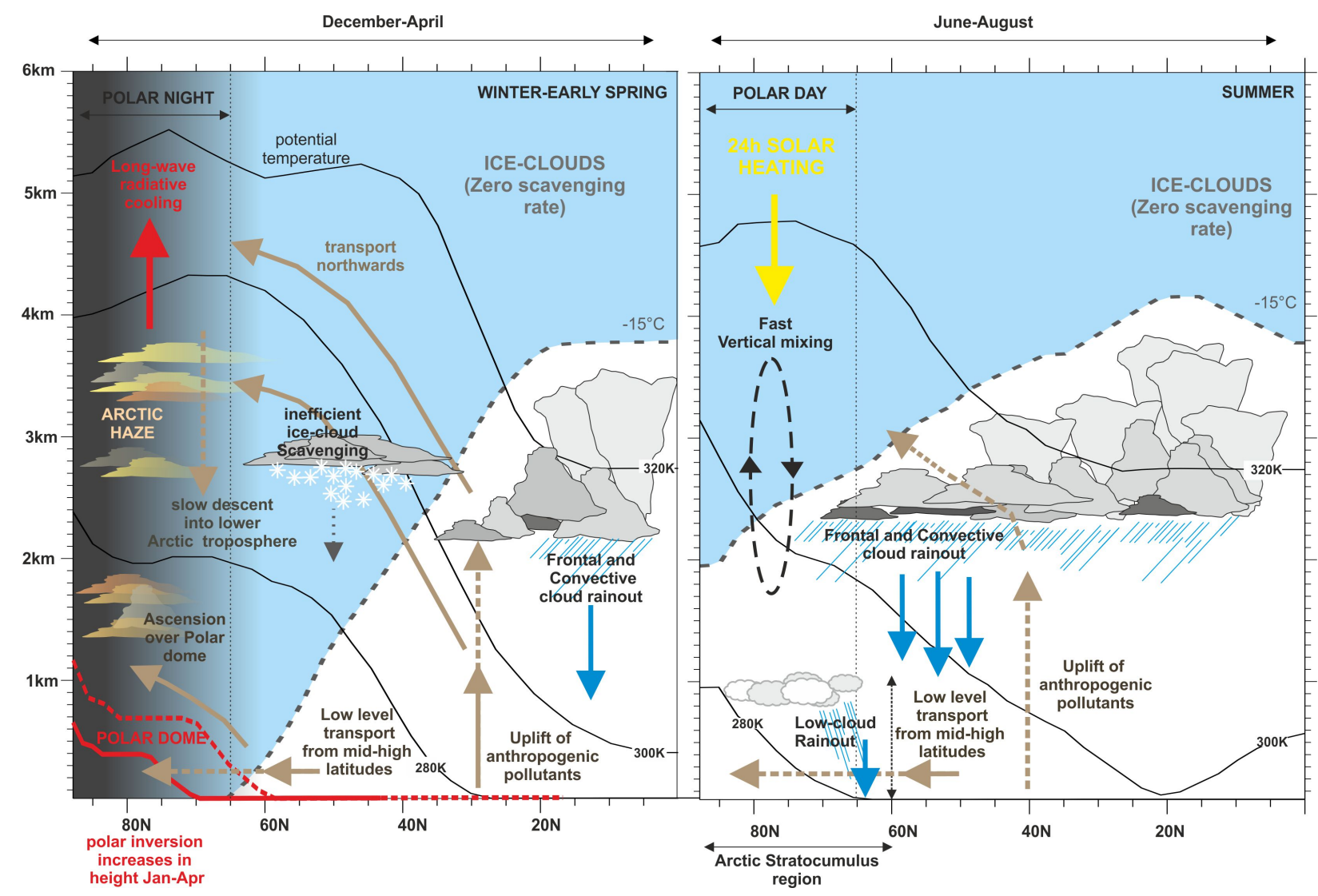

Fig. 11. Schematic showing major transport pathways and removal processes affecting the seasonal cycle in Arctic aerosol concentrations from December-April (left) and June-August (right). Transport pathways are labelled in brown with dashed lines indicating weak transport paths. Wet deposition processes are labelled in blue. Meteorological processes are labelled as required with zonal potential temperature isotherms (used in GLOMAP) shown as black solid lines. Long-wave radiative processes are shown in red while short-wave are in yellow. The $-15^{\circ} \mathrm{C}$ zonal isotherm (ice-phase cloud temperature threshold) is shown as a dashed line and calculated from atmospheric temperatures diagnosed in GLOMAP. Light blue shading indicates atmospheric region where scavenging is deemed ice-phase and so suppressed.

Our results are also consistent with the coupled-climate model studies of Bourgeois and Bey (2011) and Liu et al. (2011), which found that reducing the scavenging efficiency of ice and mixed-phase clouds decreased model bias compared to observations. In addition, reducing ice and mixedphase cloud scavenging rates in both studies reversed the modeled seasonal trend in aerosol concentrations resulting in a winter to early spring $\mathrm{BC}$ and $\mathrm{SO}_{4}$ maximum similar to that of the DRIZZICE simulations discussed here. Likewise, the CTM study by Huang et al. (2010) noted that the seasonal cycle in $\mathrm{BC}$ aerosol was driven by the seasonal cycle in local Arctic scavenging rates. However, here we suggest that the increase in winter-spring $\mathrm{BC}$ and $\mathrm{SO}_{4}$ aerosol also stems from a reduction in scavenging during long-range high-level transport (as well as local suppression), a conclusion also noted by Bourgeois and Bey (2011).

Figure 11 summarises the effects of ice-cloud and drizzle scavenging processes in the context of the major transport pathways to the Arctic identified in the Lagrangian study
Stohl (2006). These transport routes into the Arctic are defined by Stohl (2006) as: (1) low-level transport from the mid-latitudes followed by ascent over the polar inversion, (2) low-level transport directly into the Arctic boundary layer, and (3) uplift at lower latitudes followed by adiabatic ascent and transport into the Arctic free troposphere. In the summer, low-level transport through paths [1] and [2] is frequent from European anthropogenic sources and boreal forest fires, while transport from lower latitudes through path [3] is considerably weakened. In winter, transport path [2] occurred almost exclusively through Siberia (where surface temperatures are sufficiently low that air-mass entry into the polar dome is thermodynamically possible) but high-level transport through pathway [3] was found to be frequent from North American, European and Asian sources (Stohl, 2006).

From December to February, high-altitude deposition rates decrease substantially in DRIZZICE simulations due to the suppression of ice-cloud scavenging in the free troposphere (Fig. 10). The increase in winter concentrations of aged $\mathrm{SO}_{4}$ 
and $\mathrm{BC}$ in the Arctic boundary layer in DRIZZICE suggests that transport (via pathways [1] and [3]) is a significant source of Arctic aerosol in GLOMAP during this period. The absence of low-level drizzling clouds in winter makes drizzle scavenging unimportant as a controlling mechanism. It also means that aerosol transport into the free troposphere through path [3] is not scavenged at low levels after it is mixed down in the Arctic.

In summer, analysis of the latitude dependence of the integrated atmospheric column scavenging flux in the drizzle simulations shows that scavenging increases sharply at the edge of the Arctic stratocumulus zone. The onset of scavenging removes low-level aerosol mass entering the Arctic. Thus inclusion of drizzle actually results in a reduced allcloud scavenging flux above $70^{\circ} \mathrm{N}$ because aerosol concentrations are lower (Fig. 9c). From this result we can infer that in summer transport through paths [1] and [2] is both the dominant transport mechanism in GLOMAP and that this pathway is very strongly suppressed by drizzle scavenging. However, the predominance of low-level transport and the generally higher temperatures means that the suppression of scavenging in ice-clouds becomes much less important.

Drizzle scavenging in the Arctic effectively "filters" boundary layer air transported north of $60^{\circ}$. Summertime surface aerosol concentrations between $60^{\circ}$ and $75^{\circ} \mathrm{N}$ are reduced by a factor 30 below the level due to other scavenging processes (dry deposition and rain-out in frontal clouds). But the effect of the drizzle is very dependent on the assumed cloud coverage and drizzle rates, neither of which are well defined in the Arctic. ISCCP cloud cover is approximately a factor 5 lower than that retrieved from MODIS, which leads to a factor 2 less removal of $\mathrm{SO}_{4}$ but only $5 \%$ less removal of $\mathrm{BC}$ by $75^{\circ} \mathrm{N}$. The absolute differences in $\mathrm{SO}_{4}$ and $\mathrm{BC}$ concentrations in the high Arctic caused by this uncertainty are only a few nanograms per cubic metre. Further simulations are needed to test whether these differences could be climatically significant in a region with low aerosol.

The possible ramifications of an Arctic drizzle "filter" and cloud scavenging temperature threshold are worthy of further investigation in the context of climate change. In winter, when weak ice-phase scavenging permits significant aerosol transport, Arctic concentrations of $\mathrm{SO}_{4}$ and $\mathrm{BC}$ are relatively insensitive to temperature increases of less than $5^{\circ} \mathrm{C}$ due to the sharp meridional temperature gradient. However, the weaker zonal temperature gradient in spring means that higher springtime temperatures are likely to increase scavenging, potentially reducing the lifetime of the Arctic haze. In summer, increased temperatures, reduced sea ice and higher humidity will cause more drizzle and reduced aerosol concentrations and deposition rates in the high Arctic. Thus, aerosol concentrations and deposition rates in the high Arctic are likely to fall as temperatures rise.
Acknowledgements. JB was funded by a studentship from the Natural Environment Research Council and by the Met Office through a CASE partnership. KC is a Royal Society Wolfson Merit Award holder. We would like to thank Neil Gordon for providing low cloud satellite climatologies from the MODIS satellite and Dr Graham Mann for his comments and assistance. The authors acknowledge the Canadian National Atmospheric Chemistry (NAtChem) Database and its data contributing agencies/organizations for the provision of the Sulphate mass data for the years 2000-2002, used in this publication. The agency responsible for all data contributions from the the NAtChem Database is the Canadian Arctic aerosol programme. The authors acknowledge and thank the scientists and data-providers of the Norwegian institute of air research (NILU), the National ocean and atmospheric administration (NOAA) and the EMEP observation network for the provision of $\mathrm{BC}$ and sulphate mass data used in this publication.

Edited by: D. Shindell

\section{References}

Arnold, S., Chipperfield, M., and Blitz, M.: A three-dimensional model study of the effect of new temperature-dependent quantum yields for acetone photolysis, J. Geophys. Res., 110, D22305, doi:10.1029/2005JD005998, 2005.

Baumgardner, D., Subramanian, R., Twohy, C., Stith, J., and Kok, G.: Scavenging of black carbon by ice crystals over the northern Pacific, Geophys. Res. Lett., 35, L22815, doi:10.1029/2008GL035764, 2008.

Bourgeois, Q. and Bey, I.: Pollution transport efficiency toward the Arctic: Sensitivity to aerosol scavenging and source regions, J. Geophys. Res., 116, D08213, doi:10.1029/2010JD015096, 2011.

Bromwich, D., Fogt, R., Hodges, K., and Walsh, J.: A tropospheric assesment of the ERA-40, NCEP and JRA-25 global re-analyses in the polar region, J. Geophys. Res, 112, D10111, doi:10.1029/2006JD007859, 2007.

Comiso, J. C.: A rapidly declining perennial sea ice cover in the Arctic, Geophys. Res. Lett., 29, 1956, doi:10.1029/2002GL015650, 2002.

Curry, J. A., Schramm, J. L., and Ebert, E. E.: Sea Ice-Albedo Climate Feedback Mechanism, Fourth Conference on Polar Meteorology and Oceanography, 150-155, 1995.

Curry, J. A., Rossow, W. B., Randall, D., and Schramm, J. L.: Overview of Arctic Cloud and Radiation Characteristics, J. Climate, 9, 1731-1764, 1996.

Curtis, J., Wendler, G., Stone, R., and Dutton, E.: Precipitation decrease in the western Arctic, with special emphasis on Barrow and Barter island, Alaska, Int. J. Climatol., 18, 1687-1707, 1998.

Davidson, C., Honrath, R., Kadane, J., Tsay, R., Mayewski, P., Lyons, W., and Heidham, N.: The scavenging of atmospheric sulfate by Arctic snow, Atmos. Environ., 22, 871-882, 1987.

Eckhardt, S., Stohl, A., Beirle, S., Spichtinger, N., James, P., Forster, C., Junker, C., Wagner, T., Platt, U., and Jennings, S. G.: The North Atlantic Oscillation controls air pollution transport to the Arctic, Atmos. Chem. Phys., 3, 1769-1778, doi:10.5194/acp-31769-2003, 2003.

Eleftheriadis, K., Vratolis, S., and Nyeki, S.: Aerosol black carbon in the European Arctic: Measurements at Zeppelin station, 
Ny-Ålesund, Svalbard from 1998-2007, Geophys. Res. Lett., 36, L02809, doi:10.1029/2008GL035741, 2009.

Fan, S.: Impact of air pollution on wet deposition of mineral dust aerosols, Geophys. Res. Lett., 31, L02104, doi:10.1029/2003GL018501, 2004.

Ferek, R. J., Hobbs, P. V., Radke, L. F., Herring, J. A., Sturges, W. T., and Cota, G. F.: Dimethyl sulfide in the arctic atmosphere, J. Geophys. Res, 100, 26093-26104, doi:10.1029/95JD02374, 1995.

Fisher, J. A., Jacob, D. J., Purdy, M. T., Kopacz, M., Le Sager, P., Carouge, C., Holmes, C. D., Yantosca, R. M., Batchelor, R. L., Strong, K., Diskin, G. S., Fuelberg, H. E., Holloway, J. S., Hyer, E. J., McMillan, W. W., Warner, J., Streets, D. G., Zhang, Q., Wang, Y., and $\mathrm{Wu}, \mathrm{S}$.: Source attribution and interannual variability of Arctic pollution in spring constrained by aircraft (ARCTAS, ARCPAC) and satellite (AIRS) observations of carbon monoxide, Atmos. Chem. Phys., 10, 977-996, doi:10.5194/acp10-977-2010, 2010.

Garrett, T. J. and Verzella, L. L.: Looking back: An Evolving History of Arctic Aerosols, B. Am. Meteorol. Soc., 89, 299-302, doi:10.1175/BAMS-89-3-299, 2008.

Garrett, T. J., Zhao, C., and Novelli, P. C.: Assessing the relative contributions of transport efficiency and scavenging to seasonal variability in Arctic aerosol, Tellus B, 62, 190-196, doi:10.1111/j.1600-0889.2010.00453.x, 2010.

Garrett, T. J., Brattström, S., Sharma, S., Worthy, D. E. J., and Novelli, P.: The role of scavenging in the seasonal transport of black carbon and sulfate to the Arctic, Geophys. Res. Lett., 38, L16805, doi:10.1029/2011GL048221, 2011.

Gayet, J.-F., Mioche, G., Dörnbrack, A., Ehrlich, A., Lampert, A., and Wendisch, M.: Microphysical and optical properties of Arctic mixed-phase clouds. The 9 April 2007 case study, Atmos. Chem. Phys., 9, 6581-6595, doi:10.5194/acp-9-6581-2009, 2009a.

Gayet, J., Treffeisen, R., Helbig, A., Bareiss, J., Matsuki, A., Herber, A., and Schwarzenboeck, A.: On the onset of the ice phase in boundary layer Arctic clouds, J. Geophys. Res., 114, D19201, doi:10.1029/2008JD011348, 2009b.

Giannakopoulos, C., Chipperfield, M. P., Law, K. S., and Pyle, J. A.: Validation and intercomparison of wet and dry deposition schemes using $210 \mathrm{~Pb}$ in a global three-dimensional off-line chemical transport model, J. Geophys. Res., 104, 23761-23784, doi:10.1029/1999JD900392, 1999.

Gong, S. and Barrie, L.: Trends of heavy metal components in the Arctic aerosols and their relationship to the emissions in the Northern Hemisphere, Sci. Total Environ., 342, 175-183, doi:10.1016/j.scitotenv.2004.12.031, 2005.

Gong, S. L., Zhao, T. L., Sharma, S., Toom-Sauntry, D., Lavoué, D., Zhang, X. B., Leaitch, W. R., and Barrie, L. A.: Identification of trends and interannual variability of sulfate and black carbon in the Canadian High Arctic: 1981-2007, J. Geophys. Res., 115, D07305, doi:10.1029/2009JD012943, 2010.

Gorbunov, B., Baklanov, A., Kakutkina, N., Windsor, H., and Toumi, R.: Ice nucleation on soot particles, Journal Aerosol Sci., 32, 199-215, 2000.

Hahn, C. J., Warren, S. G., and London, J.: The effect of Moonlight on Observation of cloud cover at night, and application of cloud climatology, J. Climate, 8, 1429-1446, 1995.
Hegg, D. A., Clarke, A. D., Doherty, S. J., and Strom, J.: Measurements of black carbon aerosol washout ratio on Svalbard, Tellus, 63B, 891-900, doi:10.1111/j.1600-0889.2011.00577.x, 2011.

Hirdman, D., Sodemann, H., Eckhardt, S., Burkhart, J. F., Jefferson, A., Mefford, T., Quinn, P. K., Sharma, S., Ström, J., and Stohl, A.: Source identification of short-lived air pollutants in the Arctic using statistical analysis of measurement data and particle dispersion model output, Atmos. Chem. Phys., 10, 669-693, doi:10.5194/acp-10-669-2010, 2010.

Hobbs, P. and Rangno, A.: Microstructures of low and mid-level clouds over the Beufort sea, Q. J. Roy. Meteorol. Soc., 124, 2035-2071, 1998.

Hobbs, P. V., Rangno, A. L., Shupe, M., and Uttal, T.: Airborne studies of cloud structures over the Arctic Ocean and comparisons with retrievals from ship-based remote sensing measurements, J. Geophys. Res., 106, 15029-15044, doi:10.1029/2000JD900323, 2001.

Huang, L., Gong, S. L., Jia, C. Q., and Lavoue, D.: Importance of deposition processes in simulating the seasonality of the Arctic black carbon aerosol, J. Geophys. Res., 115, D17207, doi:10.1029/2009JD013478, 2010.

Hubanks, P. A., King, M. D., Platnick, S., and Pincus, R.: MODIS Atmosphere L3 Gridded Product Algorithm Theoretical Basis Document, available online at: modis.gsfc.nasa.gov/data/atbd/ atbd_mod30.pdf, aTBD Reference Number: ATBD-MOD-30, 2008.

Hurrell, J.: University corporation for atmospheric research, http: //www.cgd.ucar.edu/cas/jhurrell/nao.stat.winter.html, 2011.

IPCC: Regional climate projections in, Climate Change 2007: The Physical Basis. Contribuion of working group I to the Fourth Assessment Report of the Intergovermental panel on Climate Change, Cambridge University Press, 2007.

Jones, A., Haywood, J. M., and Boucher, O.: Aerosol forcing, climate response and climate sensitivity in the Hadley Centre climate model, J. Geophys. Res., 112, D20211, doi:10.1029/2007JD008688, 2007.

Kahl, J. D. W., Martinez, D. A., and Zaitseva, N. A.: Long-term variability in the low-level inversion layer over the Arctic ocean, Int. J. Climatol., 16, 1297-1313, 1996.

Korhonen, H., Carslaw, K., Spracklen, D. V., Mann, G., and Woodhouse, M.: Influence of oceanic dimethyl sulfide emissions on cloud condensation nuclei concentrations and seasonality over the remote Southern Hemisphere oceans: A global model study, J. Geophys. Res.-Atmos., 113, D15204, doi:10.1029/2007JD009718, 2008a.

Korhonen, H., Carslaw, K. S., Spracklen, D. V., Ridley, D. A., and Ström, J.: A global model study of processes controlling aerosol size distributions in the Arctic spring and summer, J. Geophys. Res., 113, D08211, doi:10.1029/2007JD009114, 2008b.

Lawson, R. P., Baker, B. A., Schmitt, C. G., and Jensen, T. L.: An overview of microphysical properties of Arctic clouds observed in May and July 1998 during FIRE ACE, J. Geophys. Res., 106, 14989-15014, doi:10.1029/2000JD900789, 2001.

Leon, D. C., Wang, Z., and Liu, D.: Climatology of drizzle in marine boundary layer clouds based on 1 year of data from CloudSat and Cloud-Aerosol Lidar and Infrared Pathfinder Satellite Observations (CALIPSO), J. Geophys. Res., 113, D00A14, doi:10.1029/2008JD009835, 2008. 
Liu, J., Fan, S., Horowitz, L. W., and Levy II, H.: Evaluation of factors controlling long-range transport of black carbon to the Arctic, J. Geophys. Res., 116, D00A14, doi:10.1029/2010JD015145, 2011.

Liu, Y., Keyb, J. R., Freya, R. A., Ackermana, S. A., and Menzelb, W. P.: Nightime polar cloud detection with MODIS, Remote Sens. Environ., 92, 181-194, 2004.

Lunden, J., Svensson, G., Wisthaler, A., Tjernstrom, M., Hansel, A., and Leck, C.: The vertical distribution of atmospheric DMS in the high Arctic summer, Tellus B, 62, 160-171, doi:10.1111/j.1600-0889.2010.00458.x, 2010.

Mahowald, N., Rasch, P., Eaton, B., Whittlestone, S., and Prinn, R.: Transport of (222)radon to the remote troposphere using the model of atmospheric transport and chemistry and assimilated winds from ECMWF and the National Center for Environmental Prediction NCAR, J. Geophys. Res.-Atmos., 102, 28139-28151, doi:10.1029/97JD02084, 1997.

Mann, G. W., Carslaw, K. S., Spracklen, D. V., Ridley, D. A., Manktelow, P. T., Chipperfield, M. P., Pickering, S. J., and Johnson, C. E.: Description and evaluation of GLOMAP-mode: a modal global aerosol microphysics model for the UKCA composition-climate model, Geosci. Model Dev., 3, 519-551, doi:10.5194/gmd-3-519-2010, 2010.

McConnell, J. R., Edwards, R., Kok, G. L., Flanner, M. G., Zender, C. S., Saltzman, E. S., Banta, J. R., Pasteris, D. R., Carter, M. M., and Kahl, J. D. W.: 20th-Century Industrial Black Carbon Emissions Altered Arctic Climate Forcing, Science, 317, 1381-1384, 2007.

Mitchell, M.: Visual range in the polar regions with particular reference to the Alaskan Arctic, J. Atmos. Terr. Phys., special supplement, 195-211, 1956.

Pawlowska, H.: An observational study of drizzle formation in stratocumulus clouds for general circulation model (GCM) parameterizations, J. Geophys. Res., 108, 8630, doi:10.1029/2002JD002679, 2003.

Pringle, K.: Aerosol - cloud interactions in a global model of aerosol microphysics, Ph.D. thesis, University of Leeds, 2006.

Quinn, P., Miller, T., Bates, T., Ogren, J., Andrews, E., and Shaw, G.: A 3-year record of simultaneously measured aerosol chemical and optical properties at Barrow, Alaska, J. Geophys. Res., 107, 4130, doi:10.1029/2001JD001248, 2002.

Quinn, P. K., Bates, T. S., Schulz, K., and Shaw, G. E.: Decadal trends in aerosol chemical composition at Barrow, Alaska: 19762008, Atmos. Chem. Phys., 9, 8883-8888, doi:10.5194/acp-98883-2009, 2009.

Quinn, P. K., Shaw, G., Andrews, E., Dutton, E. G., RuohoAirola, T., and Gong, S. L.: Arctic haze: current trends and knowledge gaps, Tellus B, 59, 99-114, doi:10.1111/j.16000889.2006.00238.x, 2007.

Rahn, K. A., Borys, R. D., and Shaw, G. E.: The Asian source of Arctic haze bands, Nature, 268, 713-715, doi:10.1038/268713a0, 1977.

Randerson, J. T., van der Werf, G. R., Giglio, L., Collatz, G. J., and Kasibhatla, P. S.: Global Fire Emissions Database, Version 2 (GFEDv2.1), available online: http://daac.ornl.gov/, from Oak Ridge National Laboratory Distributed Active Archive Center, Oak Ridge, Tennessee, USA doi:10.3334/ORNLDAAC/849, 2007.
Reddy, M. S. and Boucher, O.: Climate impact of black carbon emitted from energy consumption in the world's regions, Geophys. Res. Lett., 34, L11802, doi:10.1029/2006GL028904, 2007.

Rossow, W. and Duenas, E.: The International Satellite Cloud Climatology Project (ISCCP) Web site - An online resource for research, B. Am. Meteorol. Soc., 85, 167-172, 2004.

Rossow, W. and Schiffer, R.: Advances in understanding clouds from ISCCP, B. Am. Meteorol. Soc., 80, 2261-2287, 1999.

Serreze, M. C., Holland, M. M., and Stroeve, J.: Perspectives on the Arctic's shrinking sea-ice cover, Science, 315, 1533-1536, 2007.

Sharma, S.: Light absorption and thermal measurements of black carbon in different regions of Canada, J. Geophys. Res., 107, 4771, doi:10.1029/2002JD002496, 2002.

Sharma, S., Lavou, D., Cachier, H., Barrie, L., and Gong, S.: Long-term trends of the black carbon concentrations in the Canadian Arctic, J. Geophys. Res.-Atmos., 109, D15203, doi:10.1029/2003JD004331, 2004.

Sharma, S., Andrews, E., Barrie, L., Ogren, J., and Lavou, D.: Variations and sources of the equivalent black carbon in the high Arctic revealed by long-term observations at Alert and Barrow: 1989-2003, J. Geophys. Res.-Atmos., 111, D14208, doi:10.1029/2005JD006581, 2006.

Shaw, G.: The arctic haze phenomenom, B. Am. Meteorol. Soc., 76, 2403-2413, 1995.

Shaw, G. E.: Evidence for a central Eurasian source area of Arctic haze in Alaska, Nature, 299, 815-818, doi:10.1038/299815a0, 1982.

Shindell, D. and Faluvegi, G.: Climate response to regional radiative forcing during the twentieth century, Nature Geosci., 2, 294-300, doi:10.1038/ngeo473, 2009.

Shindell, D. T., Chin, M., Dentener, F., Doherty, R. M., Faluvegi, G., Fiore, A. M., Hess, P., Koch, D. M., MacKenzie, I. A., Sanderson, M. G., Schultz, M. G., Schulz, M., Stevenson, D. S., Teich, H., Textor, C., Wild, O., Bergmann, D. J., Bey, I., Bian, H., Cuvelier, C., Duncan, B. N., Folberth, G., Horowitz, L. W., Jonson, J., Kaminski, J. W., Marmer, E., Park, R., Pringle, K. J., Schroeder, S., Szopa, S., Takemura, T., Zeng, G., Keating, T. J., and Zuber, A.: A multi-model assessment of pollution transport to the Arctic, Atmos. Chem. Phys., 8, 5353-5372, doi:10.5194/acp-85353-2008, 2008.

Smith, A. J., Larson, V. E., Niu, J., Kankiewicz, A., and Carey, L. D.: Processes that generate and deplete liquid water and snow in thin midlevel mixed-phase clouds, J. Geophys, Res., 114, D12203, doi:10.1029/2008JD011531, 2009.

Spracklen, D. V., Pringle, K. J., Carslaw, K. S., Mann, G. W., Manktelow, P., and Heintzenberg, J.: Evaluation of a global aerosol microphysics model against size-resolved particle statistics in the marine atmosphere, Atmos. Chem. Phys., 7, 2073-2090, doi:10.5194/acp-7-2073-2007, 2007.

Spracklen, D. V., Pringle, K. J., Carslaw, K. S., Chipperfield, M. P., and Mann, G. W.: A global off-line model of sizeresolved aerosol microphysics: I. Model development and prediction of aerosol properties, Atmos. Chem. Phys., 5, 2227 2252, doi:10.5194/acp-5-2227-2005, 2005.

Stier, P., Feichter, J., Kinne, S., Kloster, S., Vignati, E., Wilson, J., Ganzeveld, L., Tegen, I., Werner, M., Balkanski, Y., Schulz, M., Boucher, O., Minikin, A., and Petzold, A.: The aerosol-climate model ECHAM5-HAM, Atmos. Chem. Phys., 5, 1125-1156, doi:10.5194/acp-5-1125-2005, 2005 
Stockwell, D. and Chipperfield, M.: A tropospheric chemicaltransport model:Development and validation of the model transport schemes, Q. J. Roy. Meteorol. Soc., 125, 1125-1156, 1999.

Stohl, A.: Characteristics of atmospheric transport into the Arctic troposphere, J.Geophys. Res.-Atmos., 111, D11306, doi:10.1029/2005JD006888, 2006.

Ström, J., Umegård, J., Torseth, K., Tunved, P., Hansson, H.-C., Holmén, K., Wismann, V., Herber, A., and König-Langlo, G.: One year of particle size distribution and aerosol chemical composition measurements at the Zeppelin Station, Svalbard, March 2000-March 2001, Phys. Chem. Earth, 28, 1181-1190, 2003.

Struthers, H., Ekman, A. M. L., Glantz, P., Iversen, T., Kirkevåg, A., Mårtensson, E. M., Seland, Ø., and Nilsson, E. D.: The effect of sea ice loss on sea salt aerosol concentrations and the radiative balance in the Arctic, Atmos. Chem. Phys., 11, 3459-3477, doi:10.5194/acp-11-3459-2011, 2011.

Textor, C., Schulz, M., Guibert, S., Kinne, S., Balkanski, Y., Bauer, S., Berntsen, T., Berglen, T., Boucher, O., Chin, M., Dentener, F., Diehl, T., Easter, R., Feichter, H., Fillmore, D., Ghan, S., Ginoux, P., Gong, S., Grini, A., Hendricks, J., Horowitz, L., Huang, P., Isaksen, I., Iversen, I., Kloster, S., Koch, D., Kirkevåg, A., Kristjansson, J. E., Krol, M., Lauer, A., Lamarque, J. F., Liu, X., Montanaro, V., Myhre, G., Penner, J., Pitari, G., Reddy, S., Seland, $\varnothing$., Stier, P., Takemura, T., and Tie, X.: Analysis and quantification of the diversities of aerosol life cycles within AeroCom, Atmos. Chem. Phys., 6, 1777-1813, doi:10.5194/acp-6-1777-2006, 2006.

Tiedtke, M.: A comprehensive mass flux scheme for for cumulus parameterization in large-scale models, Mon. Weather Rev., 117, 1779-1800, 1989.
Van Dingenen, R., Raes, F., and Jensen, N. R.: Evidence for anthropogenic impact on number concentration and sulfate content of cloud-processed aerosol particles over the North Atlantic, J. Geophys. Res., 100, 21057-21067, doi:10.1029/95JD02141, 1995.

van Zanten, M. C. and Stevens, B.: Observations of the Structure of Heavily Precipitating Marine Stratocumulus, J. Atmos. Sci., 62, 4327-4342, 2005.

van Zanten, M. C., Stevens, B., Vali, G., and Lenschow, D. H.: Observations of Drizzle in Nocturnal Marine Stratacumulus, J. Atmos. Sci., 62, 88-106, doi:10.1175/JAS-3355.1, 2005.

Vinogradova, A. and Ponomareva, T.: Sources and sinks of anthropogenic passive pollutants in the Russian Arctic in spring and summer seasons, Izvestiya Atmospheric and Ocean Physics, 36, 326-333, 2000.

Warneke, C., Froyd, K. D., Brioude, J., Bahreini, R., Brock, C. A., Cozic, J., de Gouw, J. A., Fahey, D. W., Ferrare, R., Holloway, J. S., Middlebrook, A. M., Miller, L., Montzka, S., Schwarz, J. P., Sodemann, H., Spackman, J. R., and Stohl, A.: An important contribution to springtime Arctic aerosol from biomass burning in Russia, Geophys. Res. Lett., 37, L01801, doi:10.1029/2009GL041816, 2010.

Wood, R.: Drizzle in Stratiform Boundary Layer Clouds. Part I: Vertical and Horizontal Structure, J. Atmos. Sci., 62, 3011-3033, doi:10.1175/JAS3529.1, 2005.

Wood, R.: Rate of loss of cloud droplets by coalescence in warm clouds, J. Geophys. Res, 111, D21205, doi:10.1029/2006JD007553, 2006.

Yang, X., Pyle, J. A., and Cox, R. A.: Sea salt aerosol production and bromine release: Role of snow on sea ice, Geophys. Res. Lett., 35, L16815, doi:10.1029/2008GL034536, 2008. 